\title{
A Unified Formulation for Free Vibration of Spherical Cap Based on the Ritz Method
}

\author{
Yuan Du $\mathbb{D},{ }^{1}$ Liping Sun, ${ }^{1}$ Xuhong Miao $\mathbb{D}^{1,},{ }^{1,2}$ Fuzhen Pang $\left(\mathbb{D},{ }^{1}\right.$ Haichao Li $\mathbb{D},{ }^{1}$ \\ and Siyu Wang ${ }^{1}$ \\ ${ }^{1}$ College of Shipbuilding Engineering, Harbin Engineering University, Harbin 150001, China \\ ${ }^{2}$ Naval Research Academy, Beijing 100161, China \\ Correspondence should be addressed to Xuhong Miao; miaoxuhong@aliyun.com
}

Received 8 April 2019; Revised 25 May 2019; Accepted 3 June 2019; Published 22 November 2019

Academic Editor: Enrico Zappino

Copyright (c) 2019 Yuan Du et al. This is an open access article distributed under the Creative Commons Attribution License, which permits unrestricted use, distribution, and reproduction in any medium, provided the original work is properly cited.

\begin{abstract}
The free vibration characteristic of spherical cap with general edge constraints is studied by means of a unified method. The energy method and Kirchhoff hypothesis are adopted to derive the formulas. The displacement functions are improved based on the domain decomposition method, in which the unified Jacobi polynomials are introduced to represent the displacement function component along circumferential direction. The displacement function component along axial direction is still the Fourier series. In addition, the spring stiffness method forms a unified format to deal with various complex boundary conditions and the continuity conditions at two adjacent segments. Then, the final solutions can be obtained based on the Ritz method. To prove the validity of this method, the results of the same condition are compared with FEM, published literatures, and experiment. The results show that the present method has the advantages of fast convergence, high solution accuracy, simple boundary simulation, etc. In addition, some numerical results of uniform and stepped spherical caps with various geometric parameters and edge conditions are reported.
\end{abstract}

\section{Introduction}

Spherical caps have been widely used in many practical engineering branches, such as pressure vessels, dome-shaped structures, submarines, and nuclear power plants. These structures usually bear different extreme loads caused by wave, wind, and even earthquakes. The dynamic excitations caused excessive vibration and even resonance in complex environmental conditions. Therefore, the analysis of free vibration of spherical caps becomes really meaningful. The related literatures are reviewed below.

Gautham and Ganesan [1] conducted a research to deal with the free vibration characteristics of isotropic and laminated orthotropic spherical caps. Based on the first-order shear deformation theory, a semianalytical shell finite element was utilized to investigate the effect of geometric configurations on vibration behavior of spherical caps. Singh and Mirza [2, 3] studied the vibration characteristics of spherical shells with various boundary restraints by means of FEM. Natural frequencies of spherical shells with different geometry parameters have been analyzed. Then, the author presented displacement fields of each segment by quintic Bezier functions, which was proved efficient and accurate using only two to four shell segments of spherical shells. Wu and Heyliger [4] analyzed the free vibration of spherical caps on the basis of twodimensional first-order shear deformable shell theory. Hermite interpolation polynomials and Fourier series were used in the azimuthal and circumferential direction, respectively.

Meanwhile, many related investigations have been conducted on typical curved shells and structures, such as the GDQ method, Fourier-Ritz method, radial basis function (RBF) method, and so on. Tornabene and Viola [5] studied the dynamical behavior of hemispherical domes and spherical shell panels on the basis of first-order shear deformation theory (FSDT) and generalized differential quadrature (GDQ) method. Jouneghani et al. [6] investigated vibrational behavior of doubly curved shells on the basis of first-order shear deformation theory (FSDT) considering porosities. Hamilton's 
principle and Navier's solution method were both utilized to derive the numerical results. Wang et al. [7-9] analyzed vibration behavior of cylindrical shells on Pasternak foundation by means of Fourier-Ritz approach. Jin et al. [10-12] analyzed vibration behavior of cylindrical shells with general boundary restraints by means of a generalized solution. The vibration behavior of a thin cylindrical shell with simply supported edges was studied by Wu et al. [13] by means of Hamilton's principle. Lagrange principle and Hamilton's principle were utilized by Hussain et al. [14] to investigate vibration of cylindrical shell resting on Winkler and Pasternak elastic foundations. Zhou et al. [15] analyzed the free vibration features of cylindrical shells with elastic edge conditions. The method of wave propagations was utilized on the basis of Flügge thin shell theory. The author presented the displacement function by Chebyshev polynomials and Fourier series. Tornabene et al. [16] presented the radial basis function (RBF) method to study vibration behavior of composite curved cases. Brischetto et al. [17] introduced the zig-zag function to overcome the discontinuity of displacement function; free vibration of curved plates was analyzed. Shi et al. [18] analyzed free vibration of double-curved shallow shell structures by means of the improved Fourier series method (IFSM); the excellent convergence and accuracy of the presented method have been proved. Li et al. [19-22] extended the modified Fourier-Ritz approach to evaluate the free vibration of rectangular plate, sector plate, and cylindrical, conical, and spherical panels and shells of revolution with general boundary conditions. Lee et al. [23] applied Flügge's thin shell theory and Rayleigh's energy method to analyze the free vibration characteristics of the joined spherical-cylindrical shell with general edge constraints. In addition, a modal test was conducted to validate the dependability of the method. Shi et al. [24] analyzed vibration behavior of double-curved shallow shells with complex edges on the basis of the spectral-geometric Ritz method. The displacement component was expressed as the assembly of Fourier series and assistant functions. The reliability and exactness of the method was proved through the comparison between present method, FEM, and published literatures. Wang et al. $[25,26]$ also proposed a unified formulation to investigate vibration behavior of curved shells.

Meanwhile, structures with stepped thickness exist widely in engineering application. The dynamic features of this kind of structure also attract researcher's attention. Qu et al. [27, 28] put forward the domain decomposition method to investigate vibration behavior of stepped and homogeneous conical shells with various boundary restraints. Zhang and Xiang [29] studied the vibration behavior of cylindrical shells with stepped thickness by means of the state-space technique and domain decomposition method. The influence of shell thickness ratios, locations of stepwise thickness variations, and step thickness ratios were also discussed. Khalifa [30] investigated the vibration behavior of stepped cylindrical shells; however, the solution process was realized through combination of the transfer matrix approach and the Romberg integration method. Fazzolari [31] carried out an investigation of vibration characteristic of curved shells on the basis of the dynamic stiffness method and higher order shear deformation theory.
Xie et al. [32] combined Flügge's thin shell theory with the power series method to investigate vibration characteristic of stepped curved shells with different edge conditions.

As we can see from the literature review, most studies mentioned above are restricted to classical edge constraints, such as clamped, hinged, and free boundary. To the authors' knowledge, few research studies have been conducted to study the vibration characteristics of uniform and stepped spherical caps with elastic edge conditions. Therefore, a unified method is necessary and meaningful to establish to solve the vibration behavior of uniform and stepped spherical caps with elastic edge conditions. On the basis of theory of thin shell and the domain decomposition method, spherical caps are separated into sections along the meridian direction. The displacement components of spherical caps along meridian and circumferential directions are presented by Jacobi polynomials and Fourier series. The boundary restraints and the internal interfaces between two adjacent parts of spherical cap are simulated through the penalty method. Final solutions are derived on the basis of the Rayleigh-Ritz method.

\section{Theoretical Model}

2.1. Description of the Model. The geometry symbol and coordinate system of uniform and stepped spherical cap are displayed in Figure 1. The spherical cap is defined in a spherical coordinate system $(\varphi, \theta, \delta)$; the displacements of the middle shore surface along meridian, circumferential, and normal orientations are, respectively, represented by $u$, $v$, and $w . h$ and $h_{i}$, respectively, denote the thickness of uniform and stepped spherical cap. The symbols $R, R_{\mathrm{c}}, C_{\mathrm{s}}$, and $\varphi_{1}$ denote the horizontal radius, radius, the center, and center angle of spherical cap, respectively. Figure 2 shows the differential element of the shell.

To increase the accuracy of calculations, the spherical cap considered in current research is partitioned into $N_{\mathrm{p}}$ shell segments along meridian direction. In addition, these sections are considered as single component in the current research. For stepped spherical cap, the number of partition sections is related to the stepped number.

2.2. Energy Functional Expressions of Spherical Cap. Based on the thin shell theory and Kirchhoff hypothesis [33-35], relationship between strain, stress, and displacement of the $i$ th part of spherical cap can be obtained. By means of Hooke's law, stresses corresponding to strains mentioned above are expressed as follows:

$$
\left\{\begin{array}{c}
\sigma_{\varphi}^{i} \\
\sigma_{\theta}^{i} \\
\sigma_{\varphi \theta}^{i}
\end{array}\right\}=\left[\begin{array}{ccc}
Q_{11} & Q_{12} & 0 \\
Q_{21} & Q_{22} & 0 \\
0 & 0 & Q_{66}
\end{array}\right]\left\{\begin{array}{c}
e_{\varphi}^{i} \\
e_{\theta}^{i} \\
\gamma_{\varphi \theta}^{i}
\end{array}\right\},
$$

where $\sigma_{\varphi}^{i}$ and $\sigma_{\theta}^{i}$ are stresses along normal directions and $\sigma_{\varphi \theta}^{i}$ is the shear stress. $e_{\varphi}^{i}, e_{\theta}^{i}$, and $\gamma_{\varphi \theta}^{i}$ correspond to normal strains and shear strains, respectively. The signification of $i$ means $i$ th section of the spherical cap. The parameters $Q_{i, j}(i, j=1,2,6)$ signify the relation between stresses and strains. The expressions of $Q_{i, j}$ are as follows: 


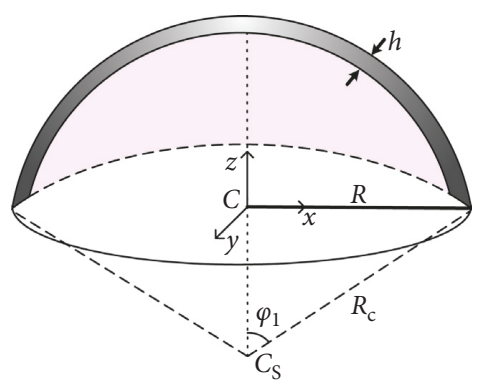

(a)

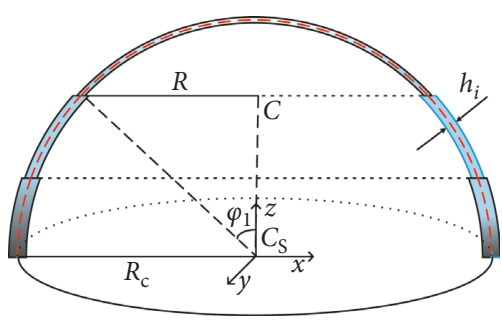

(b)

FIGURE 1: Symbols of geometric parameters and coordinates of spherical cap. (a) Uniform spherical cap. (b) Stepped spherical cap.

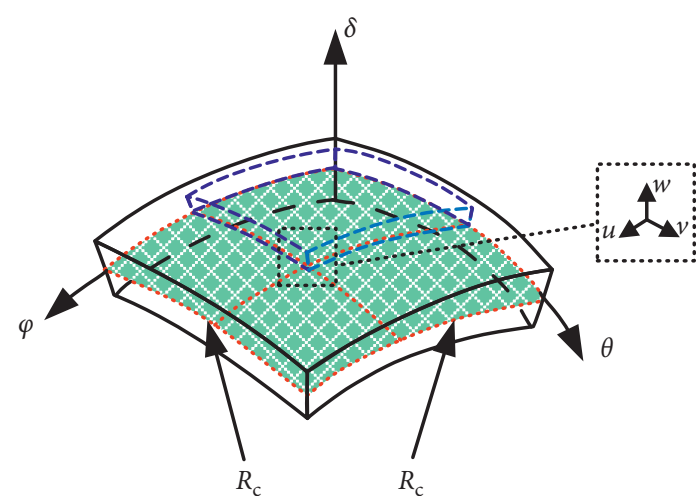

FIgURE 2: Differential element of spherical cap.

$$
\begin{aligned}
& Q_{11}=Q_{22}=\frac{E}{1-v^{2}}, \\
& Q_{12}=Q_{21}=\frac{\nu E}{1-v^{2}}, \\
& Q_{66}=\frac{E}{2(1+v)},
\end{aligned}
$$

where $E$ and $\nu$ denote Young's modulus and Poisson's ratio, respectively. Based on the elasticity theory, the expression for strain energy stored in the spherical cap during elastic deformation is

$$
U^{i}=\frac{1}{2} \int_{V}\left(\sigma_{\varphi}^{i} e_{\varphi}^{i}+\sigma_{\theta}^{i} e_{\theta}^{i}+\sigma_{\varphi \theta}^{i} \gamma_{\varphi \theta}^{i}\right) d V
$$

where $d V$ is the volume of element. The volume can be expressed as equation (4) in shell coordinates. In the formulation (4), $R_{\mathrm{c}}$ is the radius of spherical cap; in addition, $-h / 2 \leq z \leq h / 2$.

$$
d V=\left(1+\frac{z}{R_{\mathrm{c}}}\right)^{2} R_{\mathrm{c}}^{2} \sin \varphi d \varphi d \theta d z
$$

For the thin spherical cap, some items are simplified. The energy function is rewritten as follows:

$$
U^{i}=\frac{E h}{2\left(1-v^{2}\right)} \iint\left[Q_{0}^{i}+\frac{h^{2}}{12}\left(Q_{1}^{i}+Q_{2}^{i}\right)\right] R_{\mathrm{c}}^{2} \sin \varphi d \varphi d \theta .
$$

$Q_{0}^{i}, Q_{1}^{i}$, and $Q_{2}^{i}$ given in equation (5) are defined as follows:

$$
\begin{aligned}
& Q_{0}^{i}=\left(\varepsilon_{\varphi}^{i}\right)^{2}+\left(\varepsilon_{\theta}^{i}\right)^{2}+2 \nu \varepsilon_{\varphi}^{i} \varepsilon_{\theta}^{i}+\frac{1-\nu}{2}\left(\varepsilon_{\varphi \theta}^{i}\right)^{2}, \\
& Q_{1}^{i}=\left(k_{\varphi}^{i}\right)^{2}+\left(k_{\theta}^{i}\right)^{2}+2 \nu k_{\varphi}^{i} k_{\theta}^{i}+\frac{1-v}{2}\left(k_{\varphi \theta}^{i}\right)^{2}, \\
& Q_{2}^{i}=-\frac{1-v}{R_{c}} \varepsilon_{\varphi \theta}^{i} k_{\varphi \theta}^{i}+\frac{1-v}{2} \frac{1}{R_{c}^{2}}\left(\varepsilon_{\varphi \theta}^{i}\right)^{2} .
\end{aligned}
$$

Meanwhile, the kinetic energy of spherical cap is defined as follows:

$$
T^{i}=\frac{\rho h}{2} \iint\left[\left(\dot{u}^{i}\right)^{2}+\left(\dot{v}^{i}\right)^{2}+\left(\dot{w}^{i}\right)^{2}\right] R_{\mathrm{c}}^{2} \sin \varphi d \varphi d \theta
$$

where the dot above $u, v$, and $w$ represents differentiation of displacement components with respect to time. The kinetic energy expression of equation (7) can be rewritten as

$$
T^{i}=\frac{\rho h \omega^{2}}{2} \iint\left[\left(u^{i}\right)^{2}+\left(v^{i}\right)^{2}+\left(w^{i}\right)^{2}\right] R_{\mathrm{c}}^{2} \sin \varphi d \varphi d \theta
$$

where $\omega$ denotes angle frequency of the spherical cap.

2.3. Edge Conditions and Connective Constraints of the Spherical Cap. In the current research, the continuity and the boundary restraints of spherical caps are simulated on the basis of the penalty method. $k_{u}, k_{v}$, and $k_{w}$ represent the preassigned stiffness of the translational spring along $u, v$, and $w$ directions; meanwhile, $k_{r}$ denotes stiffness of rotational spring. Translational and rotational spring stiffness values are, namely, penalty parameters. In other words, arbitrary boundary restraints can be generated by assigning the penalty parameters at appropriate values. Stiffness values corresponding to general boundary restraints are displayed in Table 1 . To simplify the study, CE, SSE, and FE, respectively, denote clamped edge, shear support edge, and free edge. The spherical cap with elastic boundary restraints is displayed in Figure 3. The potential energy stored in the boundary springs can be written as follows: 
TABLE 1: Spring stiffness values corresponding to various edge conditions.

\begin{tabular}{|c|c|c|c|c|}
\hline $\mathrm{BC}$ & $k_{u, 0}, k_{u, 1}$ & $k_{v, 0}, k_{v, 1}$ & $k_{w, 0}, k_{w, 1}$ & $k_{r, 0}, k_{r, 1}$ \\
\hline FE & 0 & 0 & 0 & 0 \\
\hline SSE & $10^{14}$ & $10^{14}$ & $10^{14}$ & 0 \\
\hline $\mathrm{CE}$ & $10^{14}$ & $10^{14}$ & $10^{14}$ & $10^{14}$ \\
\hline Axial elastic support & $k_{\mathrm{b}}$ & 0 & 0 & 0 \\
\hline Circumferential elastic support & 0 & $k_{\mathrm{b}}$ & 0 & 0 \\
\hline Radial elastic support & 0 & 0 & $k_{\mathrm{b}}$ & 0 \\
\hline Rotational elastic support & 0 & 0 & 0 & $k_{\mathrm{b}}$ \\
\hline
\end{tabular}

$$
\begin{aligned}
U_{\mathrm{b}}= & \frac{1}{2} \int_{0}^{2 \pi}\left\{k_{u, 0} u_{0}^{2}+k_{v, 0} v_{0}^{2}+k_{w, 0} w_{0}^{2}\right. \\
& \left.+k_{r, 0}\left[-\frac{\left(u_{0}-\partial w_{0} / \partial \varphi_{0}\right)}{R_{\varphi_{0}}}\right]^{2}\right\} R_{\mathrm{c}} \sin \varphi d \theta \\
& +\frac{1}{2} \int_{0}^{2 \pi}\left\{k_{u, 1} u_{1}^{2}+k_{v, 1} v_{1}^{2}+k_{w, 1} w_{1}^{2}\right. \\
& \left.+k_{r, 1}\left[-\frac{\left(u_{1}-\partial w_{1} / \partial \varphi_{1}\right)}{R_{\varphi_{1}}}\right]^{2}\right\} R_{\mathrm{c}} \sin \varphi d \theta
\end{aligned}
$$

where $k_{s, 0}(s=u, v, w, r)$ and $k_{s, 1}$, respectively, denote spring stiffness value on the top and bottom side of spherical cap. The potential energy of the springs connecting two adjacent sections of the spherical cap is expressed as follows:

$$
\begin{aligned}
U_{s}^{i}= & \frac{1}{2} \int_{0}^{2 \pi}\left\{k_{u}\left(u^{i}-u^{i+1}\right)^{2}+k_{v}\left(v^{i}-v^{i+1}\right)^{2}+k_{w}\left(w^{i}-w^{i+1}\right)^{2}\right. \\
& \left.+\frac{k_{r}}{R_{s}^{2}}\left[\left(u^{i}-\frac{\partial w^{i}}{\partial \varphi}\right)-\left(u^{i+1}-\frac{\partial w^{i+1}}{\partial \varphi}\right)\right]^{2}\right\}_{i, i+1} R_{\mathrm{c}} \sin \varphi d \theta
\end{aligned}
$$

where the superscripts $i$ and $i+1$, respectively, represent the $i$ th and $i+1$ th section of the spherical cap. As a result, the total potential energy corresponds to boundary restraints, and connective relations are signified as

$$
U_{\mathrm{BC}}=U_{\mathrm{b}}+\sum_{i=1}^{N_{\mathrm{p}}-1} U_{s}^{i},
$$

where $N_{\mathrm{p}}$ is the number of divided segments mentioned above. Thus, the complex boundary restraints can be easily fulfilled by setting appropriate stiffness values to boundary spring.

2.4. Unified Solutions and Calculation Procedures. Suitable displacement function is a key point in guaranteeing the accuracy of solution. The displacement and rotation components of spherical cap are expressed as Jacobi and Fourier series, respectively.

As displayed in the classical references, Jacobi multinomials [36] are valued within the limit of $\phi \in[-1,1]$. Typical Jacobi polynomials $P_{i}^{(\alpha, \beta)}(\phi)$ of degree $i$ are written as follows in the current method:

$$
\begin{aligned}
& P_{0}^{\alpha, \beta}(\phi)=1 \\
& P_{1}^{\alpha, \beta}(\phi)=\frac{\alpha+\beta+2}{2} \phi-\frac{\alpha-\beta}{2} \\
& P_{i}^{\alpha, \beta}(\phi)=\frac{(\alpha+\beta+2 i-1)\left\{\alpha^{2}-\beta^{2}+\phi(\alpha+\beta+2 i)(\alpha+\beta+2 i-2)\right\}}{2 i(\alpha+\beta+i)(\alpha+\beta+2 i-2)} P_{i-1}^{\alpha, \beta}(\phi)-\frac{(\alpha+i-1)(\beta+i-1)(\alpha+\beta+2 i)}{i(\alpha+\beta+i)(\alpha+\beta+2 i-2)} P_{i-2}^{\alpha, \beta}(\phi) .
\end{aligned}
$$

The Jacobi polynomials are generalized polynomials containing Chebyshev, Legendre, and Gegenbauer polynomials. For example, the choice $\alpha=\beta=0$ yields the Legendre polynomials, while choosing $\alpha=\beta=1 / 2$ gives the Chebyshev polynomials. The use of Jacobi polynomials makes the choice of admissible function more flexible and generalized in this paper. The displacement components of the spherical cap along meridian, circumferential, and normal orientations can be written as

$$
\begin{gathered}
u=\sum_{m=0}^{M} \sum_{n=0}^{N} U_{m n} P_{m}^{(\alpha, \beta)}(\phi) \cos (n \theta) e^{i \omega t} \\
v=\sum_{m=0}^{M} \sum_{n=0}^{N} V_{m n} P_{m}^{(\alpha, \beta)}(\phi) \sin (n \theta) e^{i \omega t} \\
w=\sum_{m=0}^{M} \sum_{n=0}^{N} W_{m n} P_{m}^{(\alpha, \beta)}(\phi) \cos (n \theta) e^{i \omega t}
\end{gathered}
$$




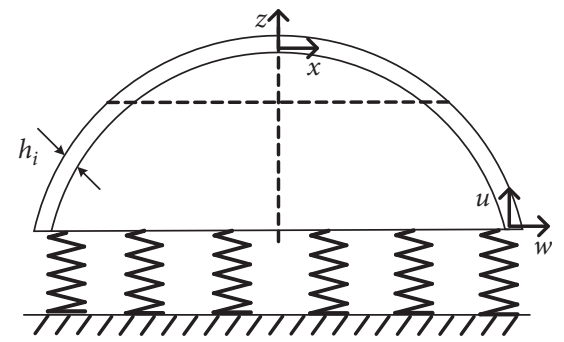

FIGURE 3: Spherical cap with elastic boundary restraints.
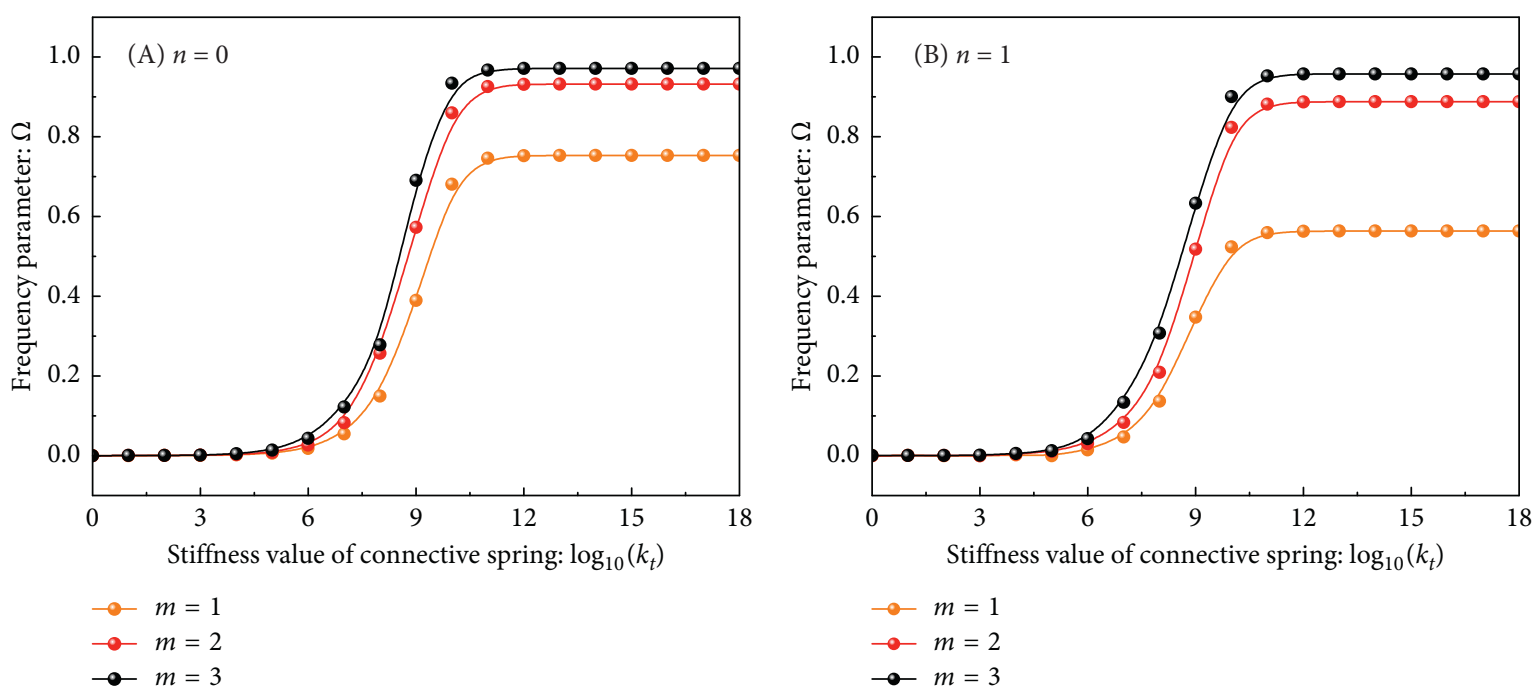

$\because-m=1$

$\multimap m=2$

$\multimap m=3$
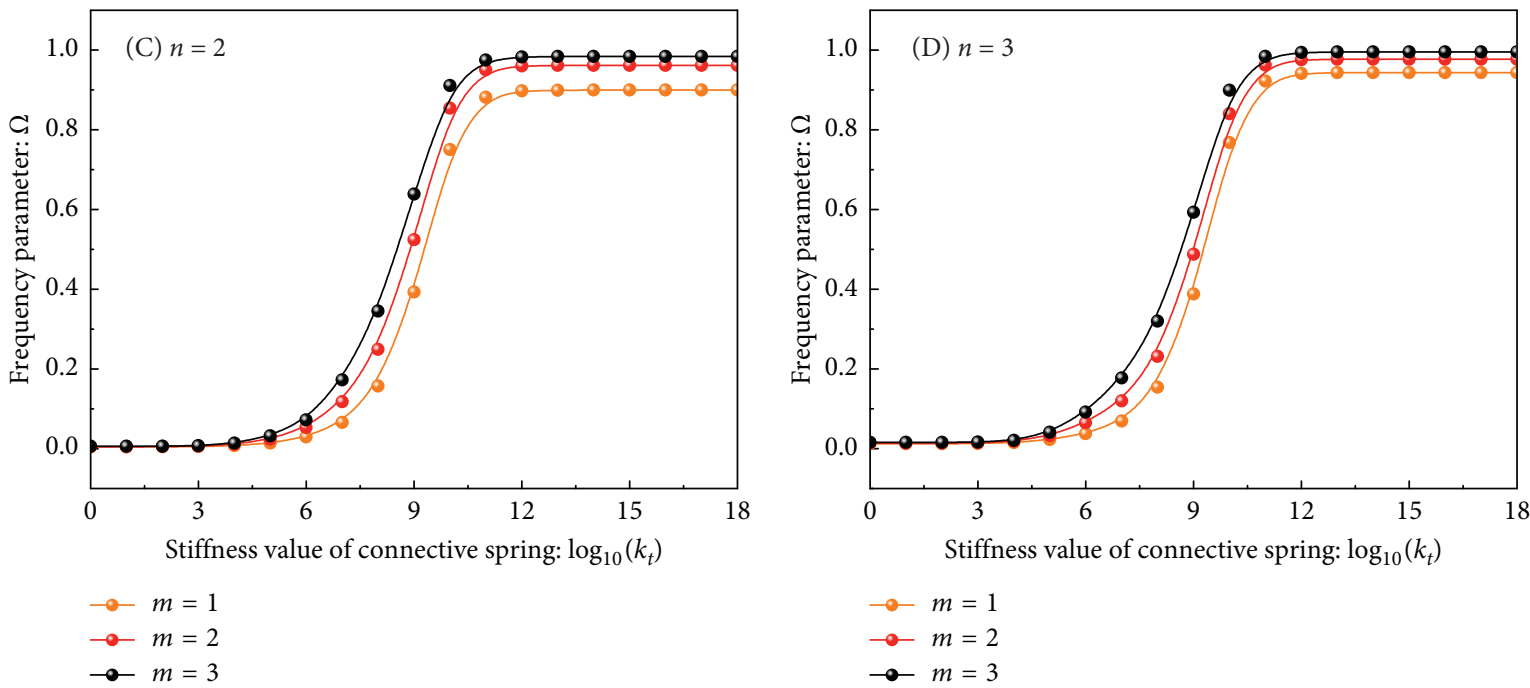

(a)

Figure 4: Continued. 

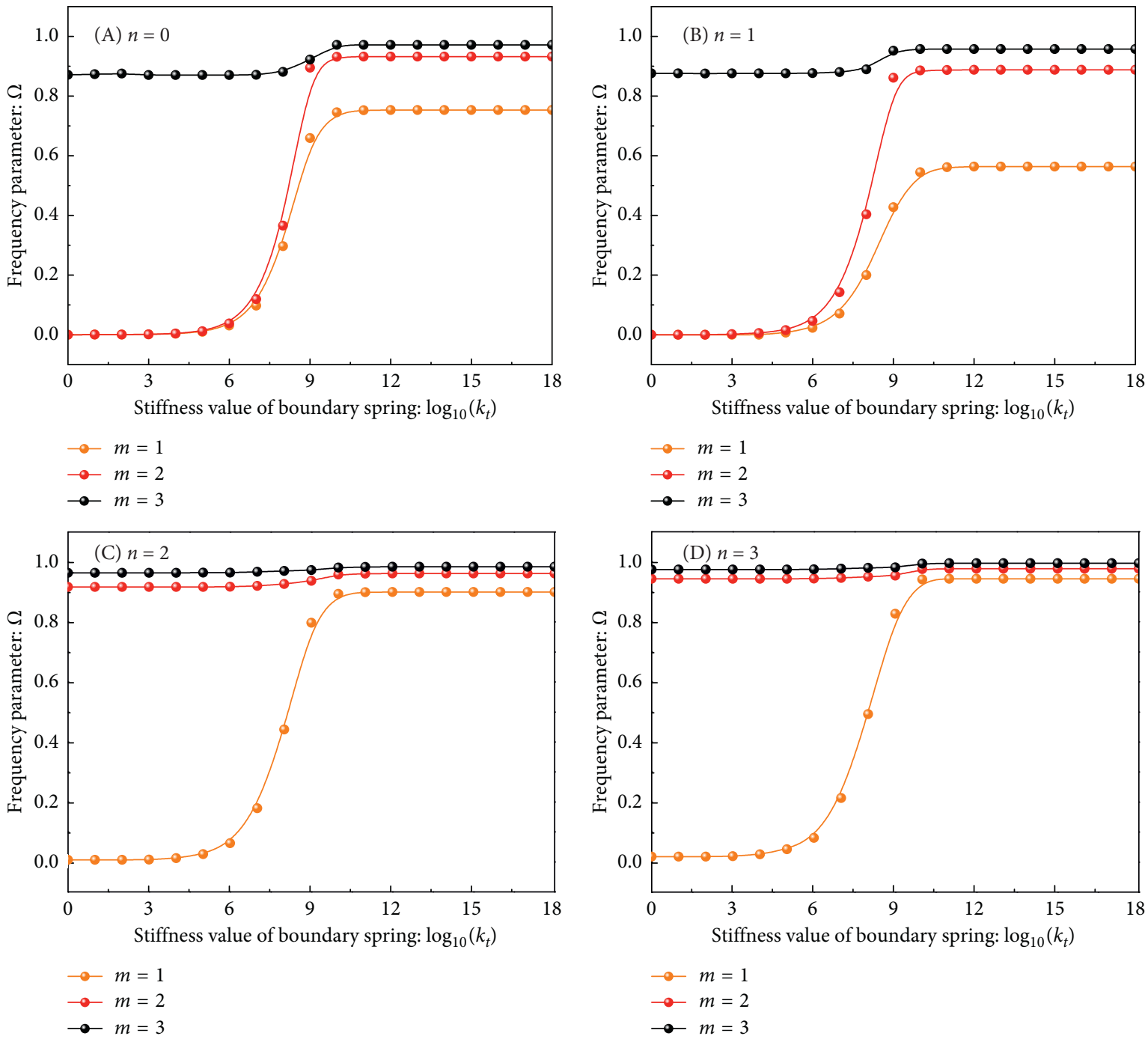

(b)

FIGURE 4: Nondimensional frequency $\Omega$ of spherical cap with different spring stiffness values: (a) connective spring; (b) boundary spring.

where $U_{m n}, V_{m n}$, and $W_{m n}$ are the Jacobi expanded coefficients corresponding to each displacement component; $P_{m}^{(\alpha, \beta)}(\phi)$ are the Jacobi polynomials of $m$ th order displacement components along axial direction; $t$ signifies time; and $\omega$ denotes the circular frequency. $n$ and $m$ signify the circumferential and axial wavenumber of the corresponding mode shape, respectively. $M$ and $N$ are the maximum order of displacement admissible functions. A linear transformation $\varphi_{\xi}=\left[\left(\varphi_{\xi}^{i+1}-\varphi_{\xi}^{i}\right) / 2\right] \phi+\left(\varphi_{\xi}^{i+1}+\varphi_{\xi}^{i}\right) / 2$ is conducted to transform $\varphi \in\left[\varphi^{i}, \varphi^{i+1}\right]$ into range $\phi \in[-1,1]$. The total Lagrangian energy function of the spherical cap can be expressed as

$$
L=\sum_{i=1}^{N}\left(T^{i}-U^{i}\right)-U_{\mathrm{BC}}
$$

Based on the Rayleigh-Ritz method, the total energy of spherical cap can be minimized with respect to the Jacobi coefficients:

$$
\frac{\partial \mathbf{L}}{\partial \vartheta}=0, \quad \vartheta=U_{m n}, V_{m n}, W_{m n} .
$$

Substituting equations (5)-(14) into equation (15), the discretized equation of vibration of the spherical cap can be expressed as the matrix form as

$$
\left(K-\omega^{2} M\right) T=0 .
$$

Symbols $K$ and $M$ of equation (16) separately signify stiffness matrix and mass matrix of the spherical cap. The detailed description of equation (16) is given in Appendix. The matrix of unknown Jacobi coefficients is denoted as symbol $T$. The eigenvalues of spherical cap are, namely, modal frequencies that can be easily achieved by solving equation (16). Meanwhile, mode shapes of spherical cap can be obtained by the substitution of the corresponding eigenvectors into components of displacement. 
TABLE 2: Convergence study of the frequency parameters $\omega R_{\mathrm{S}} \sqrt{\rho\left(1-\mu^{2}\right) / E}$ with respect to the section number of spherical cap $\left(N_{\mathrm{p}}\right)$.

\begin{tabular}{|c|c|c|c|c|c|c|c|c|c|c|c|c|c|}
\hline \multirow{2}{*}{$n$} & \multirow{2}{*}{$m$} & \multicolumn{9}{|c|}{ Number of the segments $\left(N_{\mathrm{p}}\right)$} & \multirow{2}{*}{ Ref [2] } & \multirow{2}{*}{ Ref [39] } & \multirow{2}{*}{ FEM } \\
\hline & & 2 & 3 & 4 & 5 & 6 & 7 & 8 & 9 & 10 & & & \\
\hline \multirow{5}{*}{1} & 1 & 0.8229 & 0.8229 & 0.8228 & 0.8228 & 0.8228 & 0.8228 & 0.8228 & 0.8228 & 0.8228 & 0.8247 & 0.8228 & 0.8226 \\
\hline & 2 & 0.9147 & 0.9146 & 0.9145 & 0.9145 & 0.9145 & 0.9145 & 0.9145 & 0.9145 & 0.9145 & 0.9184 & 0.9145 & 0.9144 \\
\hline & 3 & 0.9448 & 0.9443 & 0.9445 & 0.9445 & 0.9445 & 0.9445 & 0.9445 & 0.9445 & 0.9445 & 0.9485 & 0.9446 & 0.9445 \\
\hline & 4 & 0.9708 & 0.9707 & 0.9703 & 0.9703 & 0.9703 & 0.9703 & 0.9703 & 0.9703 & 0.9703 & 0.9772 & 0.9705 & 0.9704 \\
\hline & 5 & 1.0101 & 1.0099 & 1.0098 & 1.0098 & 1.0098 & 1.0098 & 1.0098 & 1.0098 & 1.0098 & 1.0228 & 1.0099 & 1.0098 \\
\hline \multirow{5}{*}{2} & 1 & 0.9195 & 0.9194 & 0.9193 & 0.9193 & 0.9193 & 0.9193 & 0.9193 & 0.9193 & 0.9193 & 0.9215 & 0.9192 & 0.9193 \\
\hline & 2 & 0.9508 & 0.9507 & 0.9505 & 0.9505 & 0.9505 & 0.9505 & 0.9505 & 0.9505 & 0.9505 & 0.9528 & 0.9504 & 0.9505 \\
\hline & 3 & 0.9791 & 0.979 & 0.9787 & 0.9787 & 0.9787 & 0.9787 & 0.9787 & 0.9787 & 0.9787 & 0.9819 & 0.9788 & 0.9788 \\
\hline & 4 & 1.0169 & 1.0167 & 1.0165 & 1.0165 & 1.0165 & 1.0165 & 1.0165 & 1.0165 & 1.0165 & 1.0184 & 1.0164 & 1.0164 \\
\hline & 5 & 1.0542 & 1.0541 & 1.0541 & 1.0541 & 1.0541 & 1.0541 & 1.0541 & 1.0541 & 1.0541 & 1.0685 & 1.0538 & 1.0539 \\
\hline \multirow{5}{*}{3} & 1 & 0.9350 & 0.9349 & 0.9348 & 0.9348 & 0.9348 & 0.9348 & 0.9348 & 0.9348 & 0.9348 & 0.9369 & 0.9346 & 0.9347 \\
\hline & 2 & 0.9624 & 0.9623 & 0.9621 & 0.9621 & 0.9621 & 0.9621 & 0.9621 & 0.9621 & 0.9621 & 0.9652 & 0.9618 & 0.9620 \\
\hline & 3 & 0.9965 & 0.9964 & 0.9963 & 0.9963 & 0.9963 & 0.9963 & 0.9963 & 0.9963 & 0.9963 & 1.0007 & 0.9961 & 0.9962 \\
\hline & 4 & 1.0443 & 1.0442 & 1.0441 & 1.0441 & 1.0441 & 1.0441 & 1.0441 & 1.0441 & 1.0441 & 1.0474 & 1.0438 & 1.044 \\
\hline & 5 & 1.0938 & 1.0935 & 1.0932 & 1.0932 & 1.0932 & 1.0932 & 1.0932 & 1.0932 & 1.0932 & 1.1110 & 1.0931 & 1.0931 \\
\hline
\end{tabular}

\section{Vibration Characteristics of Spherical Cap and Discussions}

In this section, some results and discussions about free vibration characteristics of uniform and stepped spherical caps are presented to verify the exactness and flexibility of the proposed method. Based on that, some new results are obtained for uniform and stepped spherical caps subjected to general boundary conditions. The discussion is arranged as follows: firstly, the excellent convergence of the present method is demonstrated. Then, the exactness and dependability of the current method when handling vibration characteristic of uniform and stepped spherical caps are verified. Lastly, more analytical results of uniform and stepped spherical cap with classical and elastic edge conditions are displayed. The density of the material is $\rho=7850 \mathrm{~kg} / \mathrm{m}^{3}$, Poisson's ratio $\nu=0.3$, and Young's modulus is $E=210 \mathrm{GPa}$. To avoid roundoff results, nondimensional frequency parameter is used unless otherwise stated: $\Omega=\omega R_{S} \sqrt{\rho / E}$.

3.1. Convergence Studies. When the penalty parameters are not defined as a suitable value, the solution may not converge $[37,38]$. So, it is necessary to conduct the convergence study of current method. Figure 4 denotes nondimensional frequency parameters of clamped hemispherical cap with different connective and boundary spring stiffness values. The geometry dimensions and other parameters of the hemispherical cap are as follows: $R_{\mathrm{c}}=1 \mathrm{~m}, h=0.005 \mathrm{~m}$, $\alpha=\beta=-0.5$, and $N_{\mathrm{p}}=4$.

As displayed in Figure 4, the nondimensional frequency parameter converges to a stable value when the spring stiffness of connective restraints and boundary edges is, respectively, in the scope of $k_{t}=10^{12} \sim 10^{18}$ and $k_{t}=10^{11} \sim 10^{18}$. That is to say, stiffness values at this stage can ensure clamped boundary restraints. Meanwhile, when the stiffness values of boundary spring are less than $10^{4}$, the boundary conditions can be seen as free. When the spring stiffness values are in the range of $10^{5}$ to $10^{9}$, the boundary conditions can be regarded as elastic. In the current research, the spring stiffness matching with free and clamped boundary restraints is, respectively, set as 0 and $10^{14}$. The spring coefficient $k_{\mathrm{b}}$ of elastic support is set as $10^{8}$ in the current research unless otherwise stated. Thus, the spring stiffness values of the general edge conditions can be achieved as shown in Table 1 .

The nondimensional frequency parameters of the current method with different segments are compared with the results of FEM and related literature [39] in Table $2 . h / R_{\mathrm{c}}$ and $\varphi_{1}$ of spherical cap are, respectively, 0.005 and 60 degrees. The FEM analysis was conducted by means of ANSYS. The elastic support edge constraints are imitated by distributed springs which are made up by 160 COMBIN 14 elements. In addition, the spherical cap is composed of four-node element shell 63. There are 120 and 180 shell elements along meridian and circumferential directions, respectively. The mesh of the spherical cap is fine enough to guarantee the accuracy. It can be concluded from Table 2 that the current method converges well when the shell segment $\left(N_{\mathrm{p}}\right)$ is small. When the shell segment $\left(N_{\mathrm{p}}\right)$ reaches 4 , convergence and exactness are completely fulfilled. As seen in the table, a many number of shell segments are not required in this study. The subsequent calculations will be conducted when the shell segment $\left(N_{\mathrm{p}}\right)$ is set as 4 .

The percentage error of parameter $\Omega$ about hemispherical cap with different Jacobi parameters are displayed in Figure 5. The results when $\alpha=\beta=0$ are taken as the reference value. The geometric dimensions of the spherical cap in Figure 5 are same as Figure 4. Figure 5 demonstrates different Jacobi parameters almost have no effect on the results of frequency parameter $\Omega$. Meanwhile, the change trend of the frequency parameter $\Omega$ varies with the different values of circumferential wavenumber. However, even the maximum percentage error does not exceed $3 \times 10^{-5}$. That is to say, not only the special Jacobi polynomials (Legendre, Chebyshev, etc.) can be utilized, all of the polynomials can 


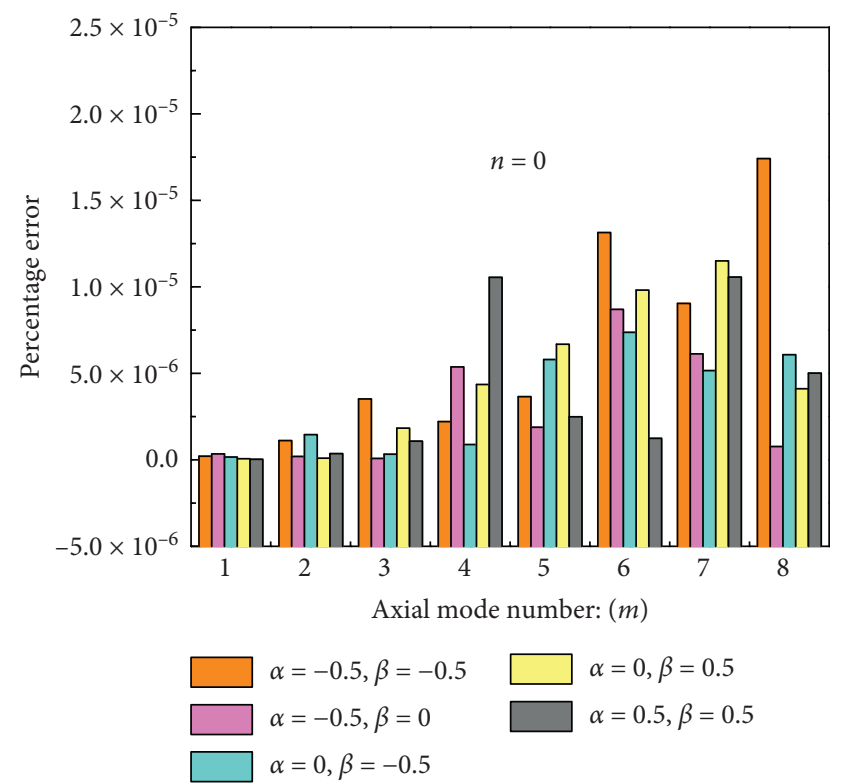

(a)

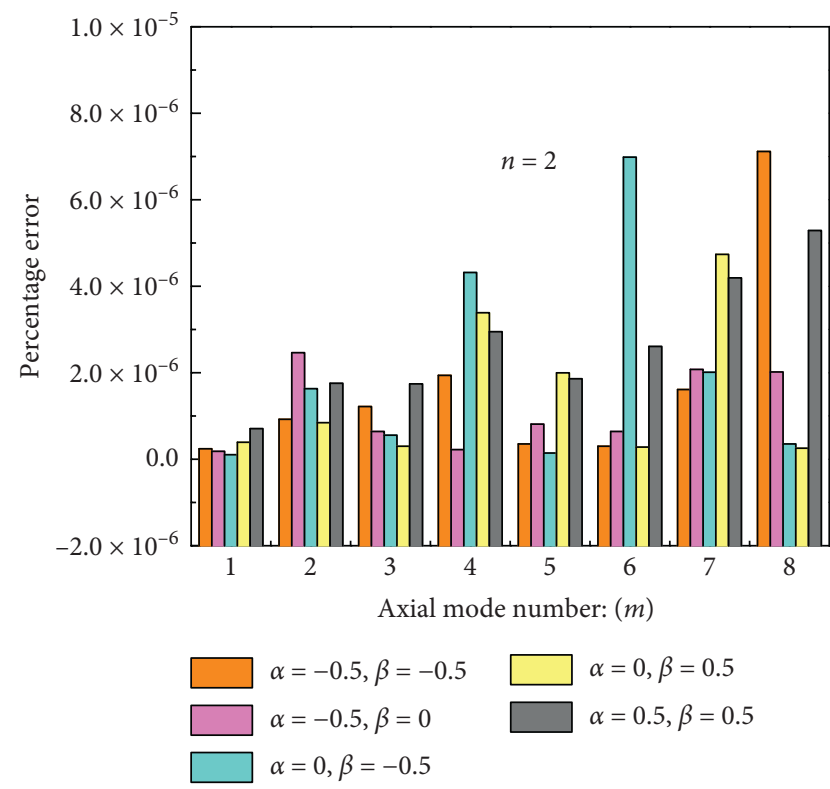

(c)

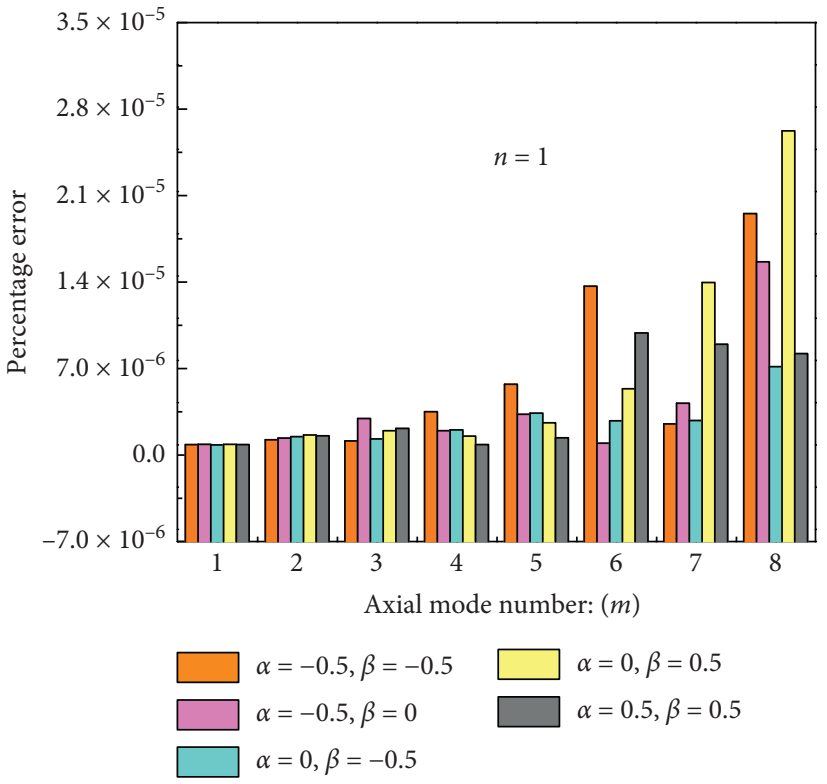

(b)

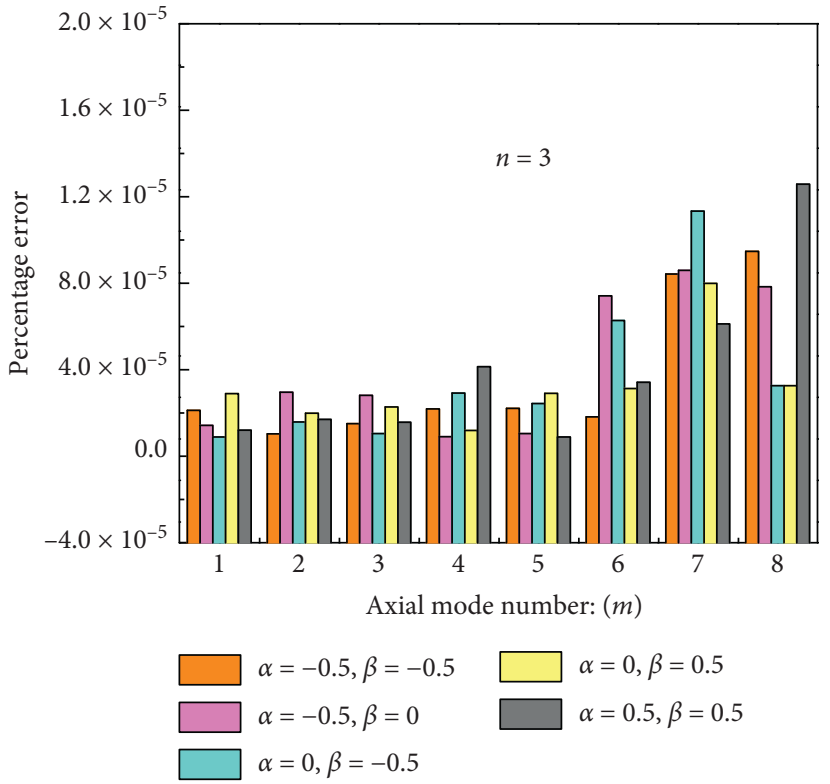

(d)

Figure 5: Fractional error of frequency parameters $\Omega$ of uniform spherical cap with different Jacobi parameters (BC: C-C).

also be used. Compared with other approaches, this is one advantage of the current method.

\subsection{Vibration Characteristics of Uniform and Stepped} Spherical Caps. Firstly, the accuracy and dependability of the current method for solving the free vibration of the uniform and stepped spherical caps will be confirmed. Afterwards, more results of spherical caps with various geometry parameters and boundary conditions are displayed. Tables 3 and 4 demonstrate the exactness and reliability of the current method for free vibration of uniform and stepped hemispherical cap by comparing with the results of related literature [39] and FEM (S4R model, 16830 elements). The geometrical parameters of hemispherical cap in Table 3 are chosen as follows: $R_{\mathrm{c}}=1 \mathrm{~m}$ and $h=0.01 \mathrm{~m}$. The radius of stepped hemispherical cap in Table 4 is the same as Table 3. Meanwhile, the thickness of the top and bottom section of stepped hemispherical cap is, respectively, $0.005 \mathrm{~m}$ and $0.01 \mathrm{~m}$.

It can be concluded from Tables 3 and 4 that the present method has excellent numerical stability when handling free vibration of uniform and stepped hemispherical cap with general boundary conditions. In addition, the tiny distinction between the current method, related literature, and FEM proves high accuracy of the current method. 
TABLE 3: Comparison of frequency parameters $\Omega$ of uniform hemispherical cap subjected to different edge conditions.

\begin{tabular}{|c|c|c|c|c|c|c|c|}
\hline \multirow[t]{2}{*}{$N$} & \multirow[t]{2}{*}{$m$} & \multicolumn{2}{|c|}{ SSE } & \multicolumn{2}{|c|}{ CE } & \multicolumn{2}{|c|}{$\begin{array}{l}\text { Axial elastic support } \\
\left(k_{\mathrm{b}}=1 e^{8}\right)\end{array}$} \\
\hline & & Present & FEM & Present & Ref [39] & Present & FEM \\
\hline \multirow{5}{*}{1} & 1 & 0.560 & 0.562 & 0.568 & 0.567 & 0.237 & 0.236 \\
\hline & 2 & 0.885 & 0.884 & 0.893 & 0.893 & 0.877 & 0.875 \\
\hline & 3 & 0.960 & 0.962 & 0.965 & 0.965 & 0.953 & 0.952 \\
\hline & 4 & 0.996 & 0.998 & 1.002 & 1.002 & 0.984 & 0.985 \\
\hline & 5 & 1.034 & 1.035 & 1.044 & 1.045 & 1.011 & 1.012 \\
\hline \multirow{5}{*}{2} & 1 & 0.900 & 0.911 & 0.901 & 0.901 & 0.173 & 0.175 \\
\hline & 2 & 0.966 & 0.968 & 0.966 & 0.966 & 0.918 & 0.946 \\
\hline & 3 & 0.997 & 0.998 & 0.998 & 0.997 & 0.968 & 0.965 \\
\hline & 4 & 1.025 & 1.023 & 1.031 & 1.029 & 0.996 & 0.997 \\
\hline & 5 & 1.066 & 1.065 & 1.079 & 1.077 & 1.029 & 1.025 \\
\hline \multirow{5}{*}{3} & 1 & 0.946 & 0.948 & 0.948 & 0.947 & 0.161 & 0.163 \\
\hline & 2 & 0.988 & 0.987 & 0.989 & 0.988 & 0.945 & 0.943 \\
\hline & 3 & 1.023 & 1.022 & 1.024 & 1.022 & 0.982 & 0.984 \\
\hline & 4 & 1.065 & 1.064 & 1.066 & 1.065 & 1.011 & 1.012 \\
\hline & 5 & 1.113 & 1.115 & 1.123 & 1.119 & 1.052 & 1.053 \\
\hline
\end{tabular}

TABLE 4: Frequency parameters $\Omega$ of stepped hemispherical cap with different boundary conditions using the current method and FEM.

\begin{tabular}{|c|c|c|c|c|c|c|c|}
\hline \multirow[t]{2}{*}{$n$} & \multirow[t]{2}{*}{$m$} & \multicolumn{2}{|c|}{ SSE } & \multicolumn{2}{|c|}{$\mathrm{CE}$} & \multicolumn{2}{|c|}{$\begin{array}{l}\text { Axial elastic support } \\
\qquad\left(k_{\mathrm{b}}=1 e^{8}\right)\end{array}$} \\
\hline & & Present & FEM & Present & FEM & Present & FEM \\
\hline \multirow{5}{*}{1} & 1 & 0.6557 & 0.6555 & 0.6478 & 0.6480 & 0.2629 & 0.2630 \\
\hline & 2 & 0.9167 & 0.9165 & 0.9119 & 0.9118 & 0.8842 & 0.8841 \\
\hline & 3 & 0.9711 & 0.9709 & 0.9656 & 0.9655 & 0.9526 & 0.9528 \\
\hline & 4 & 0.9899 & 0.9897 & 0.9839 & 0.9840 & 0.9795 & 0.9797 \\
\hline & 5 & 1.0092 & 1.0091 & 1.0048 & 1.0045 & 0.9991 & 0.9993 \\
\hline \multirow{5}{*}{2} & 1 & 0.8557 & 0.8556 & 0.8532 & 0.8530 & 0.1752 & 0.1755 \\
\hline & 2 & 0.9556 & 0.9555 & 0.9554 & 0.9555 & 0.9215 & 0.9217 \\
\hline & 3 & 0.9909 & 0.9908 & 0.9906 & 0.9902 & 0.9548 & 0.9546 \\
\hline & 4 & 1.0126 & 1.0125 & 1.0060 & 1.0061 & 0.9899 & 0.9900 \\
\hline & 5 & 1.0292 & 1.0290 & 1.0239 & 1.0240 & 1.0119 & 1.0121 \\
\hline \multirow{5}{*}{3} & 1 & 0.8762 & 0.8761 & 0.8760 & 0.8762 & 0.1608 & 0.1609 \\
\hline & 2 & 0.9765 & 0.9763 & 0.9765 & 0.9768 & 0.9157 & 0.9158 \\
\hline & 3 & 1.0059 & 1.0058 & 1.0059 & 1.0061 & 0.9764 & 0.9165 \\
\hline & 4 & 1.0392 & 1.0394 & 1.0367 & 1.0369 & 1.0055 & 1.0056 \\
\hline & 5 & 1.0597 & 1.0589 & 1.0563 & 1.0565 & 1.0374 & 1.0375 \\
\hline
\end{tabular}

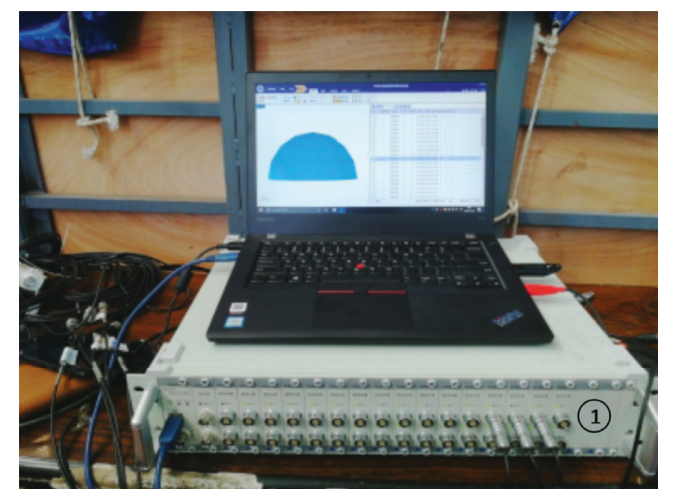

(a)

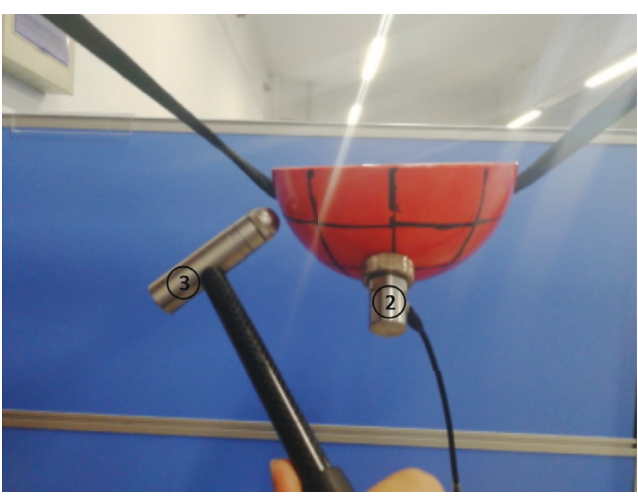

(b)

FIgURe 6: Modal measurement system and test objects. (a) Acceleration data acquisition system. (b) Impact hammer, accelerometer, and the spherical cap. 
TABLE 5: Natural frequencies $(\mathrm{Hz})$ of the tested spherical cap using different methods.

\begin{tabular}{|c|c|c|c|c|c|}
\hline Mode number $(n, m)$ & Current method & Experiment & Inaccuracy (\%) & FEM & Inaccuracy (\%) \\
\hline$(1,2)$ & 5778.6 & 5788.5 & 0.17 & 5775.9 & 0.05 \\
\hline$(2,2)$ & 6055.3 & 6072.2 & 0.28 & 6052.5 & 0.05 \\
\hline$(1,3)$ & 6310.8 & 6323.1 & 0.19 & 6303.5 & 0.12 \\
\hline$(2,3)$ & 6439.7 & 6455.2 & 0.24 & 6432.3 & 0.11 \\
\hline$(3,3)$ & 6581.7 & 6608.8 & 0.41 & 6573.9 & 0.12 \\
\hline
\end{tabular}

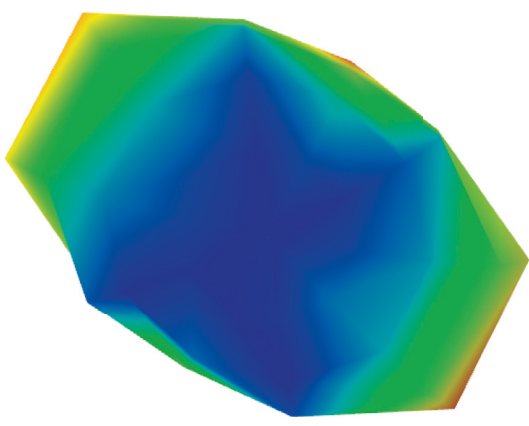

$1^{\text {st }}$ mode $(n=1, m=1)$

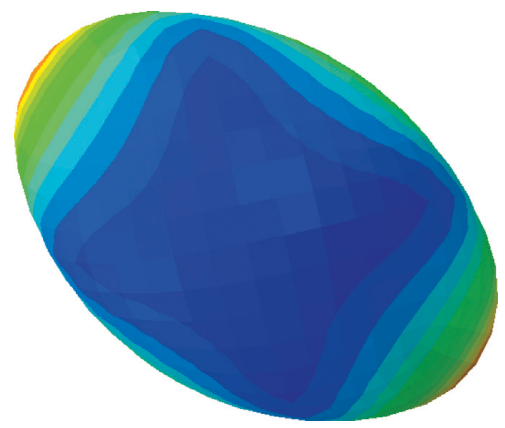

$1^{\text {st }} \operatorname{mode}(n=1, m=1)$

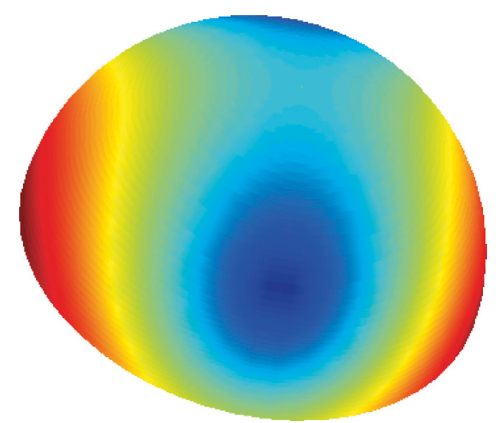

$1^{\text {st }}$ mode $(n=1, m=1)$

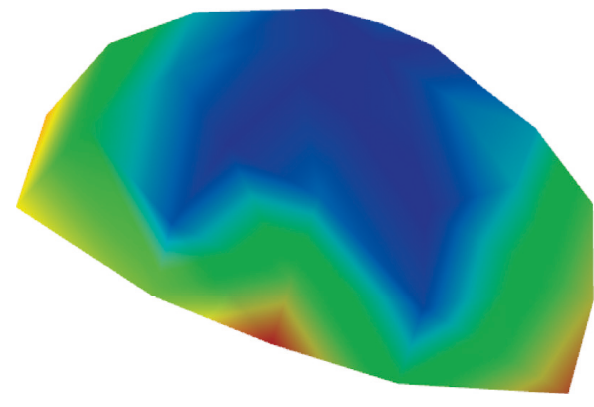

$2^{\text {nd }} \operatorname{mode}(n=2, m=1)$

(a)

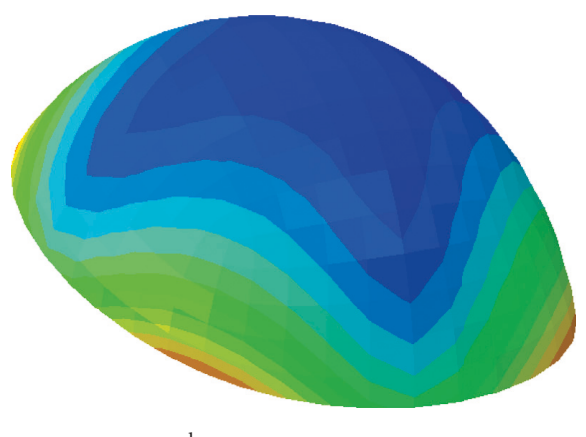

$2^{\text {nd }}$ mode $(n=2, m=1)$

(b)

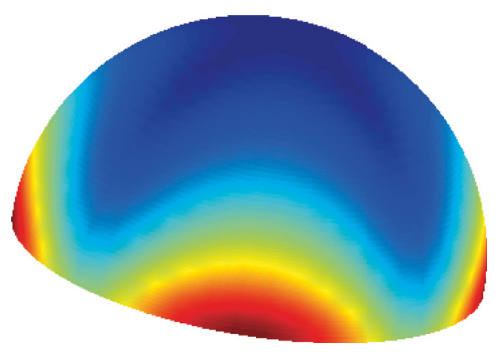

$2^{\text {nd }}$ mode $(n=2, m=1)$

(c)

Figure 7: Typical mode shapes of the spherical cap with free edge conditions using different methods. (a) Typical model test mode shapes of the spherical cap with free boundary restraint. (b) Typical mode shapes of the spherical cap with free boundary restraint using FEM software. (c) Typical mode shapes of the spherical cap with free boundary restraint using the current method.

Altogether, the current method works well when handling vibration analysis of uniform and stepped spherical cap with general boundary conditions by means of a generalized solution.
To further verify the accuracy of the current method, the experiment test focusing on free vibration of a hemispherical cap was carried out. It should be pointed out that the spherical cap is isotropic. 
TABLE 6: Nondimensional frequency parameter of uniform hemispherical cap with different edge conditions.

\begin{tabular}{|c|c|c|c|c|c|c|c|}
\hline \multirow{2}{*}{$n$} & \multirow{2}{*}{$m$} & \multicolumn{6}{|c|}{ Boundary conditions } \\
\hline & & $\mathrm{CE}$ & SSE & Axial elastic support & Circumferential elastic support & Radial elastic support & Rotational elastic support \\
\hline \multirow{5}{*}{1} & 1 & 0.5678 & 0.5601 & 0.2366 & 0.1902 & 0.1312 & 0.0112 \\
\hline & 2 & 0.8934 & 0.8852 & 0.8767 & 0.8779 & 0.8836 & 0.8764 \\
\hline & 3 & 0.9655 & 0.9604 & 0.9531 & 0.9533 & 0.9599 & 0.9536 \\
\hline & 4 & 1.0016 & 0.9959 & 0.9837 & 0.9838 & 0.9950 & 0.9865 \\
\hline & 5 & 1.0435 & 1.0343 & 1.0114 & 1.0114 & 1.0322 & 1.0182 \\
\hline \multirow{5}{*}{2} & 1 & 0.9012 & 0.9004 & 0.1734 & 0.1741 & 0.2397 & 0.0346 \\
\hline & 2 & 0.9662 & 0.9661 & 0.9176 & 0.9175 & 0.9246 & 0.9177 \\
\hline & 3 & 0.9975 & 0.9970 & 0.9682 & 0.9682 & 0.9762 & 0.9697 \\
\hline & 4 & 1.0306 & 1.0254 & 0.9964 & 0.9964 & 1.0105 & 1.0006 \\
\hline & 5 & 1.0791 & 1.0665 & 1.0293 & 1.0293 & 1.0539 & 1.0380 \\
\hline \multirow{5}{*}{3} & 1 & 0.9476 & 0.9459 & 0.1608 & 0.1611 & 0.3283 & 0.0702 \\
\hline & 2 & 0.9892 & 0.9878 & 0.9452 & 0.9452 & 0.9519 & 0.9460 \\
\hline & 3 & 1.0239 & 1.0231 & 0.9819 & 0.9819 & 0.9913 & 0.9843 \\
\hline & 4 & 1.0658 & 1.0654 & 1.0114 & 1.0114 & 1.0286 & 1.0171 \\
\hline & 5 & 1.1226 & 1.1130 & 1.0517 & 1.0517 & 1.0806 & 1.0625 \\
\hline
\end{tabular}

TABLe 7: Nondimensional frequency parameter of uniform 60 degrees spherical cap with different edge conditions.

\begin{tabular}{|c|c|c|c|c|c|c|c|}
\hline \multirow{2}{*}{$n$} & \multirow{2}{*}{$m$} & \multicolumn{6}{|c|}{ Boundary conditions } \\
\hline & & $\mathrm{CE}$ & SSE & Axial elastic support & Circumferential elastic support & Radial elastic support & Rotational elastic support \\
\hline \multirow{5}{*}{1} & 1 & 0.8668 & 0.8630 & 0.2822 & 0.2229 & 0.2215 & 0.0206 \\
\hline & 2 & 0.9727 & 0.9651 & 0.9435 & 0.9437 & 0.9540 & 0.9442 \\
\hline & 3 & 1.0305 & 1.0175 & 0.9906 & 0.9906 & 1.0120 & 0.9964 \\
\hline & 4 & 1.1231 & 1.0974 & 1.0390 & 1.0390 & 1.0861 & 1.0554 \\
\hline & 5 & 1.2777 & 1.2350 & 1.1297 & 1.1297 & 1.2057 & 1.1612 \\
\hline \multirow{5}{*}{2} & 1 & 0.9745 & 0.9720 & 0.1614 & 0.1619 & 0.3248 & 0.0536 \\
\hline & 2 & 1.0284 & 1.0280 & 0.9663 & 0.9663 & 0.9788 & 0.9686 \\
\hline & 3 & 1.0927 & 1.0848 & 1.0098 & 1.0098 & 1.0390 & 1.0192 \\
\hline & 4 & 1.2040 & 1.1700 & 1.0758 & 1.0758 & 1.1331 & 1.0980 \\
\hline & 5 & 1.3895 & 1.3347 & 1.1957 & 1.1957 & 1.2773 & 1.2350 \\
\hline \multirow{5}{*}{3} & 1 & 0.9978 & 0.9956 & 0.1513 & 0.1514 & 0.4081 & 0.0994 \\
\hline & 2 & 1.0588 & 1.0587 & 0.9844 & 0.9844 & 0.9999 & 0.9885 \\
\hline & 3 & 1.1444 & 1.1327 & 1.0352 & 1.0352 & 1.0721 & 1.0485 \\
\hline & 4 & 1.2876 & 1.2465 & 1.1245 & 1.1245 & 1.1895 & 1.1529 \\
\hline & 5 & 1.5093 & 1.4456 & 1.2772 & 1.2772 & 1.3602 & 1.3240 \\
\hline
\end{tabular}

TABLE 8: Nondimensional frequency parameter of uniform 45 degrees spherical cap with different edge conditions.

\begin{tabular}{|c|c|c|c|c|c|c|c|}
\hline \multirow{2}{*}{$n$} & \multirow{2}{*}{$m$} & \multicolumn{6}{|c|}{ Boundary conditions } \\
\hline & & $\mathrm{CE}$ & SSE & Axial elastic support & Circumferential elastic support & Radial elastic support & Rotational elastic support \\
\hline \multirow{5}{*}{1} & 1 & 0.9712 & 0.9710 & 0.3044 & 0.2513 & 0.2895 & 0.0315 \\
\hline & 2 & 1.0339 & 1.0246 & 0.9716 & 0.9716 & 0.9911 & 0.9752 \\
\hline & 3 & 1.1508 & 1.1120 & 1.0280 & 1.0280 & 1.0860 & 1.0474 \\
\hline & 4 & 1.3856 & 1.3141 & 1.1486 & 1.1486 & 1.2541 & 1.1953 \\
\hline & 5 & 1.7551 & 1.6509 & 1.3861 & 1.3862 & 1.5037 & 1.4665 \\
\hline \multirow{5}{*}{2} & 1 & 1.0161 & 1.0137 & 0.1491 & 0.1494 & 0.3964 & 0.0791 \\
\hline & 2 & 1.1034 & 1.0987 & 0.9928 & 0.9928 & 1.0212 & 1.0009 \\
\hline & 3 & 1.2618 & 1.2123 & 1.0723 & 1.0723 & 1.1463 & 1.1014 \\
\hline & 4 & 1.5552 & 1.4657 & 1.2450 & 1.2450 & 1.3556 & 1.3057 \\
\hline & 5 & 1.9888 & 1.8658 & 1.5477 & 1.5477 & 1.6534 & 1.6430 \\
\hline \multirow{5}{*}{3} & 1 & 1.0441 & 1.0438 & 0.1501 & 0.1502 & 0.4852 & 0.1424 \\
\hline & 2 & 1.1611 & 1.1453 & 1.0189 & 1.0189 & 1.0573 & 1.0320 \\
\hline & 3 & 1.3807 & 1.3159 & 1.1357 & 1.1357 & 1.2214 & 1.1753 \\
\hline & 4 & 1.7414 & 1.6371 & 1.3679 & 1.3679 & 1.4757 & 1.4420 \\
\hline & 5 & 2.2385 & 2.1012 & 1.7362 & 1.7362 & 1.8292 & 1.8450 \\
\hline
\end{tabular}


TABLE 9: Nondimensional frequency parameter of uniform 30 degrees spherical cap with different edge conditions.

\begin{tabular}{|c|c|c|c|c|c|c|c|}
\hline \multirow{2}{*}{$n$} & \multirow{2}{*}{$m$} & \multicolumn{6}{|c|}{ Boundary conditions } \\
\hline & & CE & SSE & Axial elastic support & Circumferential elastic support & Radial elastic support & Rotational elastic support \\
\hline \multirow{5}{*}{1} & 1 & 1.0509 & 1.0509 & 0.3401 & 0.3023 & 0.3932 & 0.0573 \\
\hline & 2 & 1.2192 & 1.1616 & 1.0094 & 1.0093 & 1.0797 & 1.0308 \\
\hline & 3 & 1.6567 & 1.5103 & 1.1899 & 1.1898 & 1.3506 & 1.2739 \\
\hline & 4 & 2.4021 & 2.1843 & 1.6437 & 1.6435 & 1.7893 & 1.8050 \\
\hline & 5 & 3.4110 & 3.1362 & 2.3957 & 2.3964 & 2.4889 & 2.6276 \\
\hline \multirow{5}{*}{2} & 1 & 1.1055 & 1.1004 & 0.1397 & 0.1399 & 0.5176 & 0.1421 \\
\hline & 2 & 1.3866 & 1.2949 & 1.0628 & 1.0628 & 1.1624 & 1.1030 \\
\hline & 3 & 1.9737 & 1.7928 & 1.3611 & 1.3611 & 1.5184 & 1.4768 \\
\hline & 4 & 2.8563 & 2.6055 & 1.9615 & 1.9615 & 2.0803 & 2.1540 \\
\hline & 5 & 3.9980 & 3.6856 & 2.8490 & 2.8490 & 2.8688 & 2.8690 \\
\hline \multirow{5}{*}{3} & 1 & 1.1799 & 1.1560 & 0.1892 & 0.1893 & 0.6300 & 0.2519 \\
\hline & 2 & 1.5988 & 1.4723 & 1.1532 & 1.1532 & 1.2734 & 1.2144 \\
\hline & 3 & 2.3331 & 2.1221 & 1.5893 & 1.5893 & 1.7304 & 1.7333 \\
\hline & 4 & 3.3468 & 3.0680 & 2.3315 & 2.3315 & 2.4289 & 2.5504 \\
\hline & 5 & 4.6097 & 4.2700 & 3.3471 & 3.3471 & 3.4106 & 3.6318 \\
\hline
\end{tabular}

TABLE 10: Nondimensional frequency parameter of stepped hemispherical cap with different edge conditions.

\begin{tabular}{|c|c|c|c|c|c|c|c|}
\hline \multirow{2}{*}{$n$} & \multirow{2}{*}{$m$} & \multicolumn{6}{|c|}{ Boundary conditions } \\
\hline & & $\mathrm{CE}$ & SSE & Axial elastic support & Circumferential elastic support & Radial elastic support & Rotational elastic support \\
\hline \multirow{5}{*}{1} & 1 & 0.6956 & 0.6854 & 0.2263 & 0.1749 & 0.1388 & 0.0188 \\
\hline & 2 & 0.9392 & 0.9327 & 0.9033 & 0.9041 & 0.9116 & 0.9036 \\
\hline & 3 & 0.9699 & 0.9646 & 0.9581 & 0.9580 & 0.9620 & 0.9588 \\
\hline & 4 & 0.9946 & 0.9938 & 0.9880 & 0.9880 & 0.9945 & 0.9916 \\
\hline & 5 & 1.0250 & 1.0208 & 0.9968 & 0.9978 & 1.0176 & 1.0022 \\
\hline \multirow{5}{*}{2} & 1 & 0.8180 & 0.8123 & 0.1475 & 0.1493 & 0.2365 & 0.0467 \\
\hline & 2 & 0.9777 & 0.9777 & 0.8526 & 0.8444 & 0.8526 & 0.8471 \\
\hline & 3 & 0.9899 & 0.9805 & 0.9775 & 0.9775 & 0.9776 & 0.9775 \\
\hline & 4 & 1.0115 & 1.0115 & 0.9984 & 0.9970 & 1.0017 & 1.0036 \\
\hline & 5 & 1.0522 & 1.0463 & 1.0110 & 1.0109 & 1.0129 & 1.0122 \\
\hline \multirow{5}{*}{3} & 1 & 0.8572 & 0.8557 & 0.1388 & 0.1393 & 0.2365 & 0.0931 \\
\hline & 2 & 0.9926 & 0.9921 & 0.8836 & 0.8832 & 0.8526 & 0.8856 \\
\hline & 3 & 1.0054 & 0.9986 & 0.9928 & 0.9928 & 0.9776 & 0.9930 \\
\hline & 4 & 1.0310 & 1.0310 & 1.0104 & 1.0103 & 1.0017 & 1.0266 \\
\hline & 5 & 1.0796 & 1.0704 & 1.0309 & 1.0309 & 1.0129 & 1.0309 \\
\hline
\end{tabular}

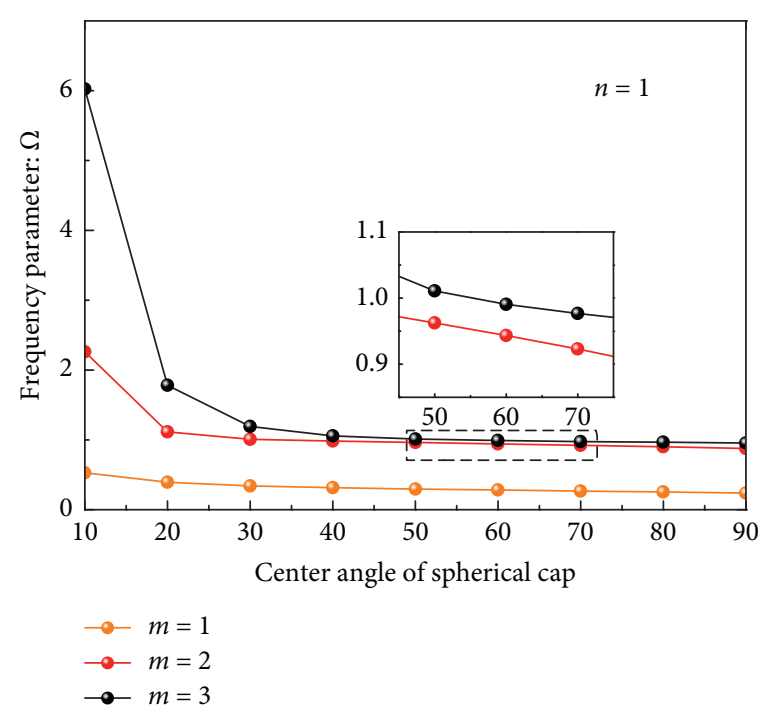

(a)

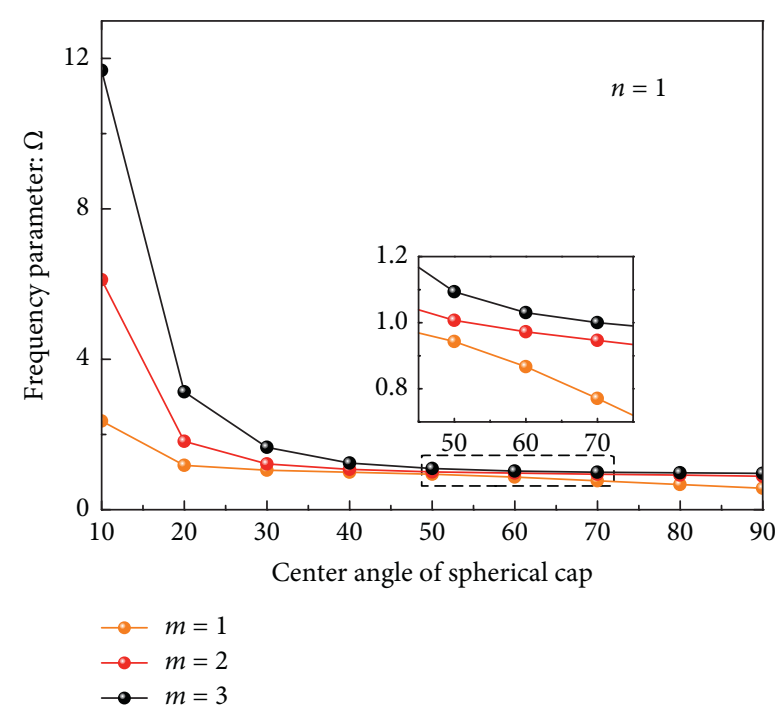

(b)

Figure 8: Continued. 


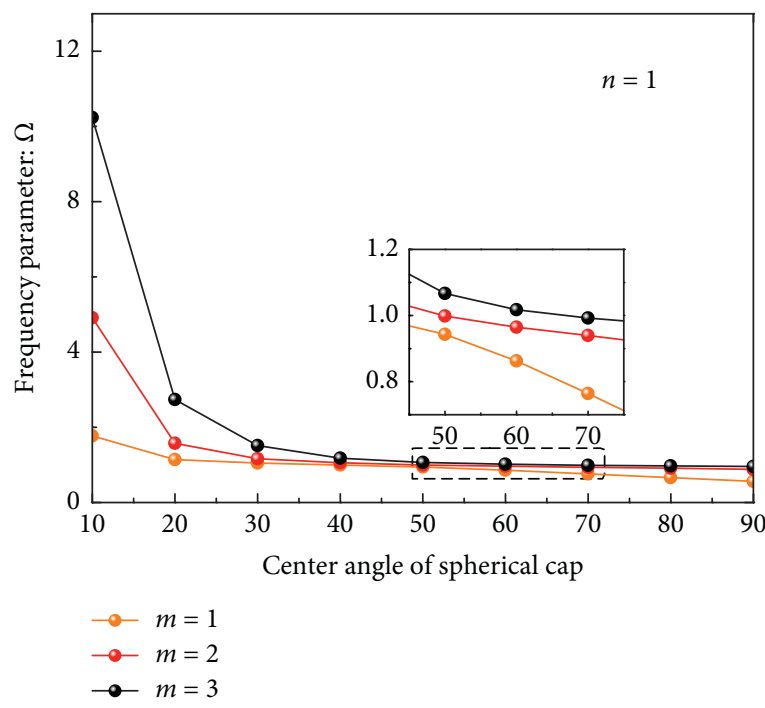

(c)

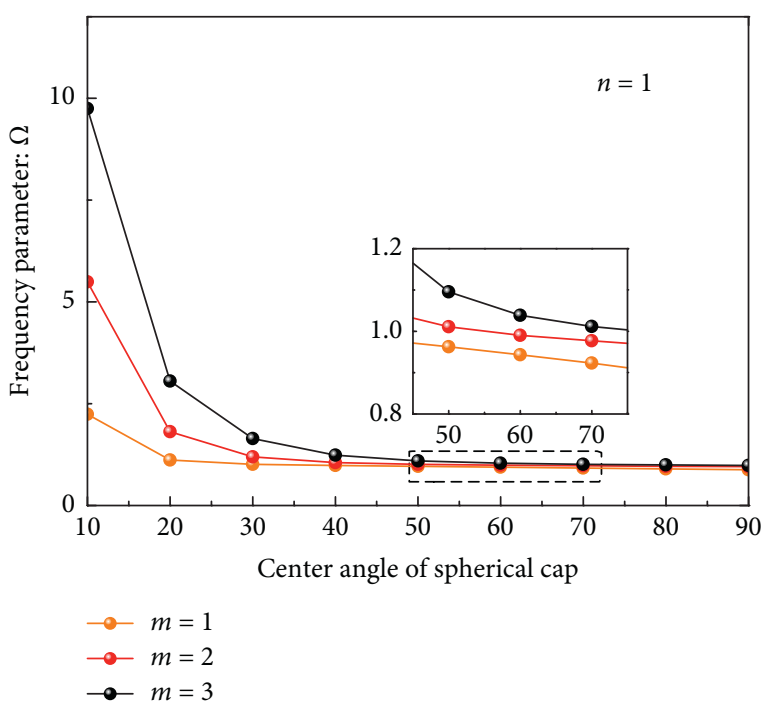

(d)

FIgURE 8: Frequency parameters $\Omega$ of uniform spherical cap with different center angles and boundary conditions. (a) Axial elastic support boundary condition. (b) Clamped boundary condition. (c) Shear support boundary condition. (d) Free boundary condition.

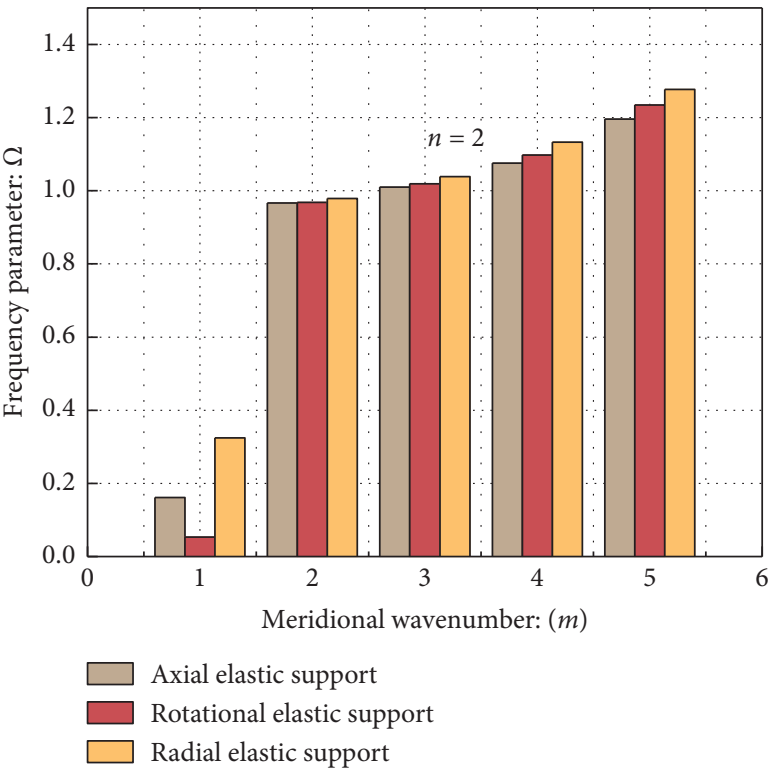

(a)

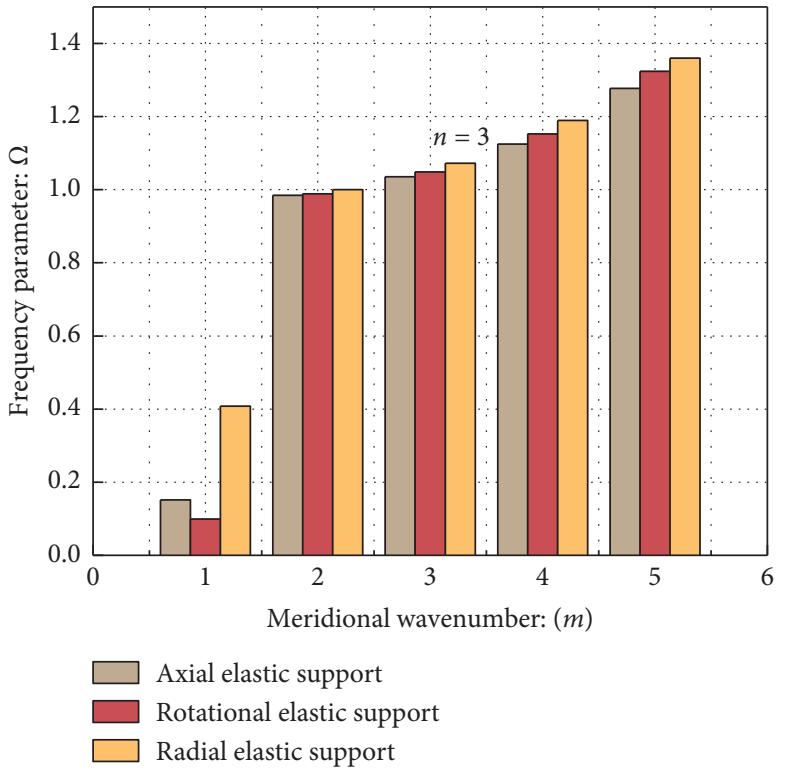

(b)

FIGURE 9: Nondimensional frequency $\Omega$ of uniform spherical cap with various elastic support edge conditions.

The material and geometrical parameters are chosen as follows: $\rho=7850 \mathrm{~kg} / \mathrm{m}^{3}, \nu=0.3, E=210 \mathrm{GPa}, R_{\mathrm{c}}=0.125 \mathrm{~m}$, and $h=0.002 \mathrm{~m}$. The boundary condition is free for isotropic spherical cap due to the restraints of test environment. The electronics used to capture the frequencies and experimental model are displayed in Figure 6. In the experiment, the hammer (no. 3 in Figure 6) was used to strike different positions of spherical cap in turn, and acceleration sensors (no. 2 in Figure 6) with sensitivity of $100 \mathrm{mv} / \mathrm{g}$ were used to collect the vibration response at the same point. Then, the time domain signals obtained by the dynamic signal testing analyzer (no. 1 in Figure 6) were transformed into frequency domain signals by Fourier transform. The final results of frequencies are shown in Table 5. Meanwhile, the mode shapes of the spherical cap using experiment, FEM, and the current method are displayed in Figure 7. It is clear that the 

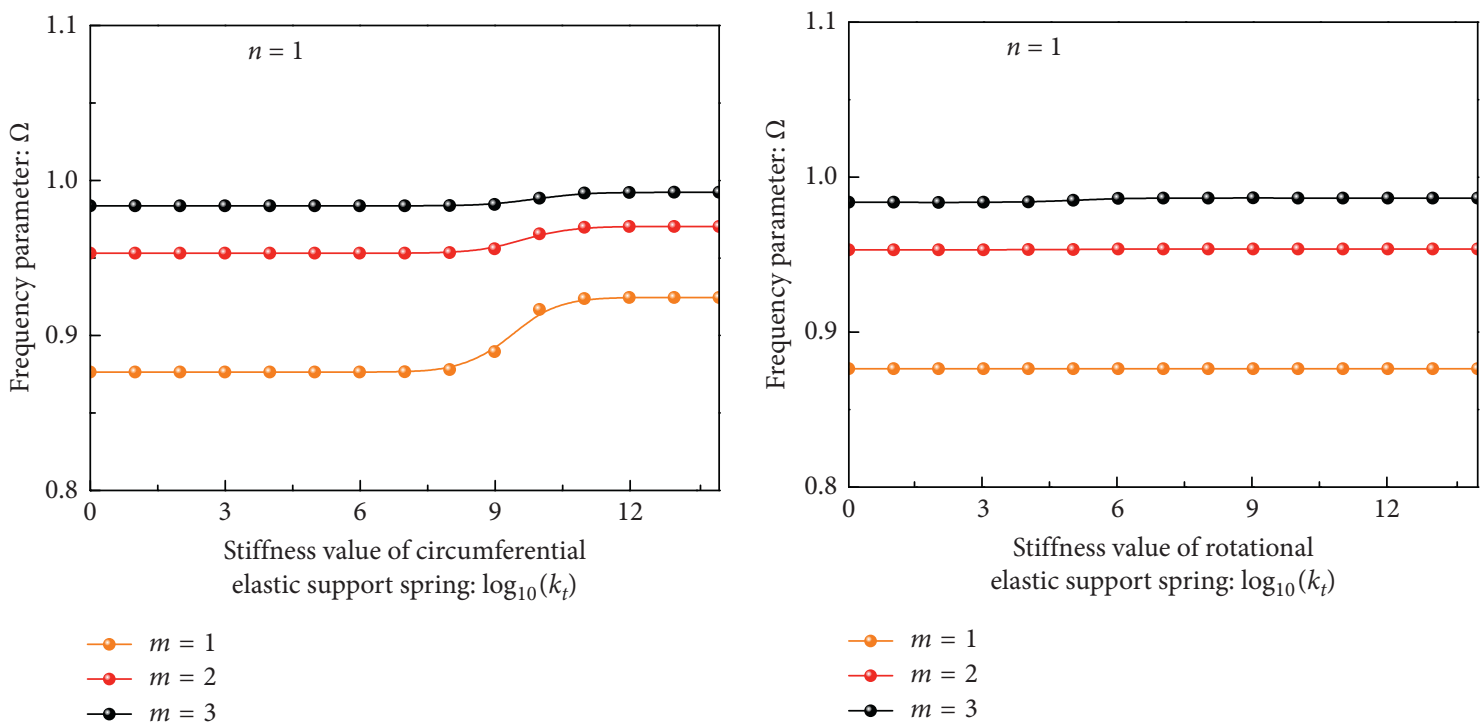

(a)

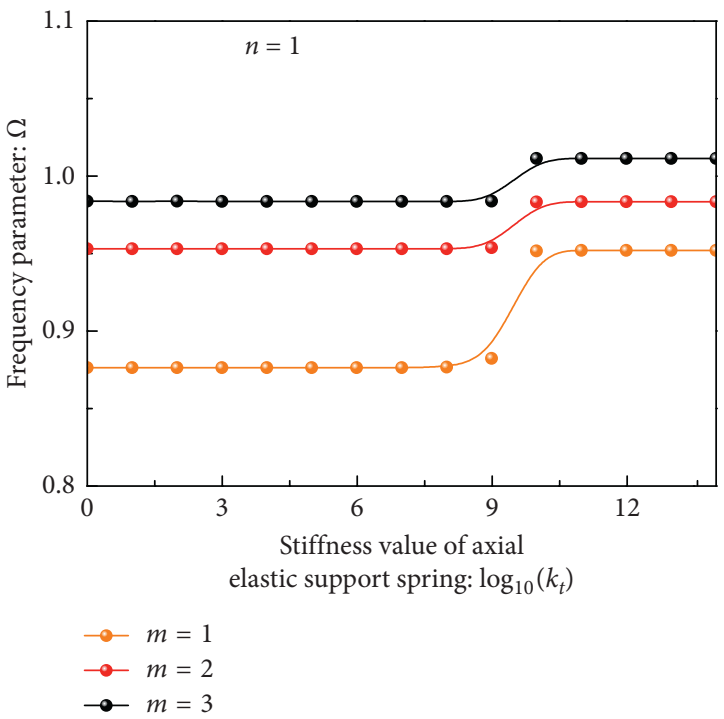

(b)

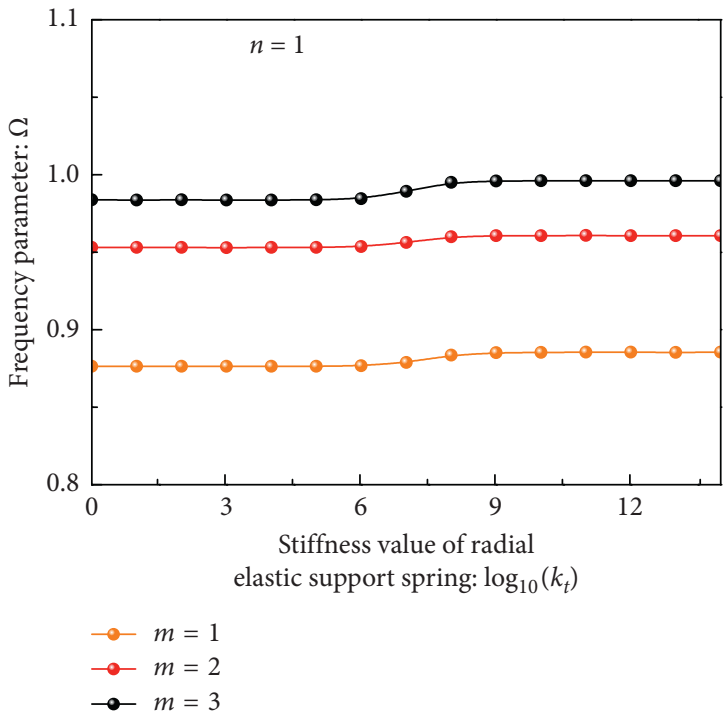

(c)

(d)

FIGURE 10: Frequency parameters $\Omega$ vs. stiffness of different elastic support springs.

frequencies and modal shapes of current method matched well with the modal test and FEM. For selected five modes, the maximum error of the present method and experiment is $0.41 \%$. The reason for the error of the present method with the test results is mainly the influence of elastic hoisting boundary and random error.

Tables 6-9 display the frequency parameter $\Omega$ of uniform spherical caps with various center angles $\varphi_{1}$ subject to general boundary conditions, in which $\varphi_{1}=30,45,60,90$ degrees are included. The radius and thickness of spherical cap are $1 \mathrm{~m}$ and $0.005 \mathrm{~m}$, respectively. Table 10 demonstrates the nondimensional frequency parameter of stepped hemispherical cap with general boundary restraints. The radius of stepped hemispherical cap in Table 10 is $R_{\mathrm{c}}=1 \mathrm{~m}$. However, the thickness of the top, middle, and bottom section of stepped hemispherical cap is, respectively, $0.005 \mathrm{~m}, 0.01 \mathrm{~m}$, and $0.015 \mathrm{~m}$. It can be seen from Tables 6-9 that frequency parameter $\Omega$ of spherical cap increases with the axial modes when the circumferential wavenumber is a certain value. Besides, it is clear that the boundary conditions have an important effect on the vibration characteristics of spherical cap.

Figure 8 shows nondimensional frequency parameters $\Omega$ of uniform spherical cap with different center angles and boundary restraints (namely axial elastic support, clamped, shear support, and free). It is easy to find that with the increase of center angle, the frequency parameter of spherical cap decreases, especially when the center angle is smaller than 50 degrees.

Figure 9 demonstrates the nondimensional frequency parameters $\Omega$ with three different elastic support boundary 
conditions (namely, axial, radial, and rotational); the second and third circumferential modes with first five meridian wavenumbers (i.e., $m=1-5$ ) are considered. Different elastic support boundary restraints affect more heavily on the frequency parameters $\Omega$ with low meridian wavenumbers.

Figure 10 displays the relation between nondimensional frequency parameters $\Omega$ and stiffness of different elastic supports. In the previous clamped boundary restraint example, we soften the axial, radial, circumferential, and rotational spring stiffness continuously from $10^{14}$ to $10^{0}$, respectively. The nondimensional frequencies $\Omega$ of the first circumferential mode and the first three meridian wavenumbers are considered. The similar trend in Figure 4 is discovered again when considering axial and circumferential elastic supports, respectively. However, the changes of stiffness value of radial and rotational spring have little effect on the frequency parameters $\Omega$.

\section{Conclusions}

The paper presents a unified solution to investigate the free vibration of uniform and stepped spherical caps with elastic support edge constraints. Nondimensional frequency parameters of spherical caps with various geometry specifications and edge conditions are displayed, which may be useful for further research studies. There are some conclusions obtained as follows:

(1) Frequency parameter $\Omega$ of spherical cap increases with the meridian wavenumber when the circumferential number is invariant.

(2) With the decrease of center angle, the frequency parameter of spherical cap increases, especially when the center angle is smaller than 50 degrees.

(3) The effect of boundary spring stiffness on frequency parameter of spherical cap varies greatly in different directions.

(4) There is almost no effect of varying the radial and rotational restraining springs on the frequency parameters, while the other restraining stiffness is kept infinite. However, different trends appear when considering axial and circumferential elastic supports.

\section{Appendix}

$$
\begin{aligned}
K & =K_{\eta}+K_{\mathrm{b}}+K_{s}, \\
M & =\operatorname{diag}\left[M^{1}, M^{2}, \cdots, M^{N}\right], \\
K_{\eta} & =\operatorname{diag}\left[K^{1}, K^{2}, \cdots, K^{N}\right], \\
K_{\mathrm{b}} & =\operatorname{diag}\left[K_{\mathrm{b} 0}, \cdots, K_{\mathrm{b} 1}\right],
\end{aligned}
$$

$$
K_{s}=\int_{0}^{2 \pi}\left[\begin{array}{cccccc}
K_{u_{i} u_{i}} & 0 & K_{u_{i} w_{i}} & K_{u_{i} u_{i+1}} & & K_{u_{i} w_{i+1}} \\
0 & K_{v_{i} v_{i}} & 0 & & K_{v_{i} v_{i+1}} & \\
K_{u_{i} w_{i}}^{T} & 0 & K_{w_{i} w_{i}} & K_{w_{i} u_{i+1}} & & K_{w_{i} w_{i+1}} \\
K_{u_{i} u_{i+1}}^{T} & & K_{w_{i} u_{i+1}}^{T} & K_{u_{i+1} u_{i+1}} & & K_{u_{i+1} w_{i+1}} \\
& K_{v_{i} v_{i+1}}^{T} & & & K_{v_{i+1} v_{i+1}} & \\
K_{u_{i} w_{i+1}}^{T} & & K_{w_{i} w_{i+1}}^{T} & K_{u_{i+1} w_{i+1}}^{T} & & K_{w_{i+1} w_{i+1}}
\end{array}\right] B d \theta
$$

$$
M^{i}=\int_{\varphi_{, i}}^{\varphi_{, i+1}} \int_{0}^{2 \pi}\left[\begin{array}{ccc}
M_{u u} & 0 & 0 \\
0 & M_{v v} & 0 \\
0 & 0 & M_{w w}
\end{array}\right] A B d \varphi d \theta
$$

$$
\begin{aligned}
M_{u u} & =\rho h U^{T} U, \\
M_{v v} & =\rho h V^{T} V, \\
M_{w w} & =\rho h W^{T} W, \\
U & =P_{m} \otimes C_{n}, \\
V & =P_{m} \otimes S_{n}, \\
W & =P_{m} \otimes C_{n},
\end{aligned}
$$

$$
P_{m}=\left[P_{0}^{(\alpha, \beta)}(\phi), P_{1}^{(\alpha, \beta)}(\phi), \cdots, P_{m}^{(\alpha, \beta)}(\phi), \cdots, P_{M}^{(\alpha, \beta)}(\phi)\right],
$$

$$
C_{n}=[\cos (0 \theta), \cos (1 \theta), \cdots, \cos (n \theta), \cdots, \cos (N \theta)]
$$

$$
S_{n}=[\sin (0 \theta), \sin (1 \theta), \cdots, \sin (n \theta), \cdots, \sin (N \theta)],
$$

$$
K_{\eta}^{i}=\int_{\varphi_{\eta, i}}^{\varphi_{\eta, i+1}} \int_{0}^{2 \pi}\left[\begin{array}{ccc}
K_{\eta, u u} & K_{\eta, u v} & K_{\eta, u w} \\
K_{\eta, u v}^{T} & K_{\eta, v v} & K_{\eta, v w} \\
K_{\eta, u w}^{T} & K_{\eta, v w}^{T} & K_{\eta, w w}
\end{array}\right] A B d \varphi d \theta
$$

$K_{\eta, u u}=K_{\mathrm{E}} u u_{\mathrm{Q} 0}+D_{\mathrm{G}}\left(u u_{\mathrm{Q} 1}+u u_{\mathrm{Q} 2}\right)$,

$K_{\eta, u v}=K_{\mathrm{E}} u v_{\mathrm{Q} 0}+D_{\mathrm{G}}\left(u v_{\mathrm{Q} 1}+u v_{\mathrm{Q} 2}\right)$

$K_{\eta, u w}=K_{\mathrm{E}} u w_{\mathrm{Q} 0}+D_{\mathrm{G}}\left(u w_{\mathrm{Q} 1}+u w_{\mathrm{Q} 2}\right)$,

$K_{\eta, v v}=K_{\mathrm{E}} v v_{\mathrm{Q} 0}+D_{\mathrm{G}}\left(v v_{\mathrm{Q} 1}+v v_{\mathrm{Q} 2}\right)$

$K_{\eta, v w}=K_{\mathrm{E}} v w_{\mathrm{Q} 0}+D_{\mathrm{G}}\left(v w_{\mathrm{Q} 1}+v w_{\mathrm{Q} 2}\right)$,

$K_{\eta, w w}=K_{\mathrm{E}} w w_{\mathrm{Q} 0}+D_{\mathrm{G}}\left(w w_{\mathrm{Q} 1}+w w_{\mathrm{Q} 2}\right)$, 


$$
\begin{aligned}
& K_{\mathrm{b} 0}=\int_{0}^{2 \pi}\left[\begin{array}{ccc}
K_{\mathrm{b} 0, u u} & 0 & K_{\mathrm{b} 0, u w} \\
0 & K_{\mathrm{b} 0, v v} & 0 \\
K_{\mathrm{b} 0, u w}^{T} & 0 & K_{\mathrm{b} 0, w w}
\end{array}\right]_{\varphi=\varphi_{0}} B d \theta, \\
& K_{\mathrm{b} 0, u u}=\left(k_{u, 0}+k_{r, 0}\right) U^{T} U, \\
& K_{\mathrm{b} 0, u w}=-k_{r, 0} \frac{1}{R_{\varphi}} U^{T} \frac{\partial W}{\partial \varphi}, \\
& K_{\mathrm{b} 0, v v}=k_{v, 0} V^{T} V \text {, } \\
& K_{\mathrm{b} 0, w w}=k_{w, 0} W^{T} W+k_{r, 0} \frac{\partial W^{T}}{\partial \varphi} \frac{\partial W}{\partial \varphi}, \\
& K_{\mathrm{b} 1}=\int_{0}^{2 \pi}\left[\begin{array}{ccc}
K_{\mathrm{b} 1, u u} & 0 & K_{\mathrm{b} 1, u w} \\
0 & K_{\mathrm{b} 1, v v} & 0 \\
K_{\mathrm{b} 1, u w}^{T} & 0 & K_{\mathrm{b} 1, w w}
\end{array}\right]_{\varphi=\varphi_{1}} B d \theta \\
& K_{\mathrm{b} 1, u u}=\left(k_{u, 1}+k_{r, 1}\right) U^{T} U, \\
& K_{\mathrm{b} 1, u w}=-k_{r, 1} \frac{1}{R_{\varphi}} U^{T} \frac{\partial W}{\partial \varphi}, \\
& K_{\mathrm{bl}, v v}=k_{v, 1} V^{T} V \\
& K_{\mathrm{b} 1, w w}=k_{w, 1} W^{T} W+k_{r, 1} \frac{\partial W^{T}}{\partial \varphi} \frac{\partial W}{\partial \varphi}, \\
& K_{u_{i} u_{i}}=\left(k_{u}+k_{r} \frac{1}{R_{\varphi}^{2}}\right) U_{i}^{T} U_{i} m, \\
& K_{u_{i} w_{i}}=-k_{r} \frac{1}{R_{\varphi}^{2}} U_{i}^{T} \frac{\partial W_{i}}{\partial \varphi} \\
& K_{v_{i} v_{i}}=k_{v} V_{i}^{T} V_{i} \text {, } \\
& K_{w_{i} w_{i}}=k_{w} W_{i}^{T} W_{i}+k_{r} \frac{1}{R_{\varphi}^{2}} \frac{\partial W_{i}^{T}}{\partial \varphi} \frac{\partial W_{i}}{\partial \varphi}, \\
& K_{u_{i} u_{i+1}}=-\left(k_{u}+k_{r} \frac{1}{R_{\varphi}^{2}}\right) U_{i}^{T} U_{i+1}, \\
& K_{u_{i} w_{i+1}}=k_{r} \frac{1}{R_{\varphi}^{2}} U_{i}^{T} \frac{\partial W_{i+1}}{\partial \varphi}, \\
& K_{w_{i} u_{i+1}}=k_{r} \frac{1}{R_{\varphi}^{2}} \frac{\partial W_{i}^{T}}{\partial \varphi} U_{i+1}, \\
& K_{v_{i} v_{i+1}}=-k_{v} V_{i}^{T} V_{i+1} \text {, }
\end{aligned}
$$

$$
\begin{aligned}
K_{w_{i} w_{i+1}} & =-k_{w} W_{i}^{T} W_{i-1}-k_{r} \frac{1}{R_{\varphi}^{2}} \frac{\partial W_{i}^{T}}{\partial \varphi} \frac{\partial W_{i+1}}{\partial \varphi}, \\
K_{u_{i+1} u_{i+1}} & =\left(k_{u}+k_{r} \frac{1}{R_{\varphi}^{2}}\right) U_{i+1}^{T} U_{i+1}, \\
K_{u_{i+1} w_{i+1}} & =-k_{r} \frac{1}{R_{\varphi}^{2}} U_{i+1}^{T} \frac{\partial W_{i+1}}{\partial \varphi}, \\
K_{v_{i+1} v_{i+1}} & =k_{v} V_{i+1}^{T} V_{i+1}, \\
K_{w_{i+1} w_{i+1}} & =k_{w} W_{i+1}^{T} W_{i+1}+k_{r} \frac{1}{R_{\varphi}^{2}} \frac{\partial W_{i+1}^{T}}{\partial \varphi} \frac{\partial W_{i+1}}{\partial \varphi} .
\end{aligned}
$$

\section{Data Availability}

The data used to support the findings of this study are included within the article.

\section{Conflicts of Interest}

The authors declare that they have no conflicts of interest.

\section{Acknowledgments}

This study was funded by the National Natural Science Foundation of China (51209052 and 51679053), National Key Research and Development Program (2016YFC0303406), Ph.D. Student Research and Innovation Fund of the Fundamental Research Funds for the Central Universities (HEUGIP201801), Fundamental Research Funds for the Central University (HEUCFD1515 and HEUCFM170113), Assembly Advanced Research Fund of China (6140210020105), and Naval Pre-Research Project, China Postdoctoral Science Foundation (2014M552661).

\section{References}

[1] B. P. Gautham and N. Ganesan, "Free vibration characteristics of isotropic and laminated orthotropic spherical caps," Journal of Sound and Vibration, vol. 204, no. 1, pp. 17-40, 1997.

[2] A. V. Singh and S. Mirza, "Asymmetric modes and associated eigenvalues for spherical shells," Journal of Pressure Vessel Technology, vol. 107, no. 1, pp. 77-82, 1985.

[3] A. V. Singh, "On vibrations of shells of revolution using bezier polynomials," Journal of Pressure Vessel Technology, vol. 113, no. 4, pp. 579-584, 1991.

[4] Y.-C. Wu and P. Heyliger, "Free vibration of layered piezoelectric spherical caps," Journal of Sound and Vibration, vol. 245, no. 3, pp. 527-544, 2001.

[5] F. Tornabene and E. Viola, "Vibration analysis of spherical structural elements using the GDQ method," Computers \& Mathematics with Applications, vol. 53, no. 10, pp. 1538-1560, 2007.

[6] F. Z. Jouneghani, R. Dimitri, M. Bacciocchi, and F. Tornabene, "Free vibration analysis of functionally graded porous doubly- 
curved shells based on the first-order shear deformation theory," Applied Sciences-Basel, vol. 7, no. 12, p. 1252, 2017.

[7] Q. Wang, D. Shi, Q. Liang, and F. Pang, "Free vibrations of composite laminated doubly-curved shells and panels of revolution with general elastic restraints," Applied Mathematical Modelling, vol. 46, pp. 227-262, 2017.

[8] Q. Wang, D. Shi, F. Pang, and F. e Ahad, "Benchmark solution for free vibration of thick open cylindrical shells on Pasternak foundation with general boundary conditions," Meccanica, vol. 52, no. 1-2, pp. 457-482, 2017.

[9] Q. Wang, D. Shi, F. Pang, and Q. Liang, "Vibrations of composite laminated circular panels and shells of revolution with general elastic boundary conditions via fourier-ritz method," Curved \& Layered Structures, vol. 3, no. 1, pp. 105-136, 2016.

[10] G. Jin, T. Ye, Y. Chen, Z. Su, and Y. Yan, "An exact solution for the free vibration analysis of laminated composite cylindrical shells with general elastic boundary conditions," Composite Structures, vol. 106, pp. 114-127, 2013.

[11] G. Jin, T. Ye, X. Ma, Y. Chen, Z. Su, and X. Xie, “A unified approach for the vibration analysis of moderately thick composite laminated cylindrical shells with arbitrary boundary conditions," International Journal of Mechanical Sciences, vol. 75, pp. 357-376, 2013.

[12] Y. Chen, G. Jin, and Z. Liu, "Free vibration analysis of circular cylindrical shell with non-uniform elastic boundary constraints," International Journal of Mechanical Sciences, vol. 74, pp. 120-132, 2013.

[13] Z. Wu, G. Yao, and Y. Zhang, "Vibration analysis of a thin eccentric rotating circular cylindrical shell," Proceedings of the Institution of Mechanical Engineers, Part C: Journal of Mechanical Engineering Science, vol. 233, no. 5, pp. 1588-1600, 2019.

[14] M. Hussain, M. N. Naeem, and M. R. Isvandzibaei, "Effect of Winkler and Pasternak elastic foundation on the vibration of rotating functionally graded material cylindrical shell," Proceedings of the Institution of Mechanical Engineers, Part C: Journal of Mechanical Engineering Science, vol. 232, no. 24, pp. 4564-4577, 2018.

[15] H. Zhou, W. Li, B. Lv, and W. L. Li, "Free vibrations of cylindrical shells with elastic-support boundary conditions," Applied Acoustics, vol. 73, no. 8, pp. 751-756, 2012.

[16] F. Tornabene, N. Fantuzzi, E. Viola, and A. J. M. Ferreira, "Radial basis function method applied to doubly-curved laminated composite shells and panels with a general higher-order equivalent single layer formulation," Composites Part B: Engineering, vol. 55, pp. 642-659, 2013.

[17] S. Brischetto, E. Carrera, and L. Demasi, "Free vibration of sandwich plates and shells by using zig-zag function," Shock and Vibration, vol. 16, no. 5, pp. 495-503, 2009.

[18] D. Y. Shi, S. Zha, H. Zhang, and Q. Wang, "Free vibration analysis of the unified functionally graded shallow shell with general boundary conditions," Shock and Vibration, vol. 2017, Article ID 7025190, 19 pages, 2017.

[19] F. Pang, H. Li, Y. Du, S. Li, H. Chen, and N. Liu, "A series solution for the vibration of mindlin rectangular plates with elastic point supports around the edges," Shock and Vibration, vol. 2018, Article ID 8562079, 21 pages, 2018.

[20] H. Li, N. Liu, F. Pang, Y. Du, and S. Li, “An accurate solution method for the static and vibration analysis of functionally graded Reissner-Mindlin rectangular plate with general boundary conditions," Shock and Vibration, vol. 2018, Article ID 4535871, 21 pages, 2018.

[21] L. Li, H. Li, F. Pang, X. Wang, Y. Du, and S. Li, “The modified Fourier-Ritz approach for the free vibration of functionally graded cylindrical, conical, spherical panels and shells of revolution with general boundary condition," Mathematical Problems in Engineering, vol. 2017, Article ID 9183924, 32 pages, 2017.

[22] H. Li, F. Pang, X. Wang, and S. Li, "Benchmark solution for free vibration of moderately thick functionally graded sandwich sector plates on two-parameter elastic foundation with general boundary conditions," Shock and Vibration, vol. 2017, Article ID 4018629, 35 pages, 2017.

[23] Y.-S. Lee, M.-S. Yang, H.-S. Kim, and J.-H. Kim, "A study on the free vibration of the joined cylindrical-spherical shell structures," Computers \& Structures, vol. 80, no. 27-30, pp. 2405-2414, 2002.

[24] D. Shi, Y. Zhao, Q. Wang, X. Teng, and F. Pang, "A unified spectro-geometric-ritz method for vibration analysis of open and closed shells with arbitrary boundary conditions," Shock and Vibration, vol. 2016, Article ID 4097123, 30 pages, 2016.

[25] Q. Wang, B. Qin, D. Shi, and Q. Liang, "A semi-analytical method for vibration analysis of functionally graded carbon nanotube reinforced composite doubly-curved panels and shells of revolution," Composite Structures, vol. 174, pp. 87109, 2017.

[26] Q. Wang, F. Pang, B. Qin, and Q. Liang, "A unified formulation for free vibration of functionally graded carbon nanotube reinforced composite spherical panels and shells of revolution with general elastic restraints by means of the Rayleigh-Ritz method," Polymer Composites, vol. 39, no. 2, pp. E924-E944, 2017.

[27] Y. Qu, Y. Chen, X. Long, H. Hua, and G. Meng, "Free and forced vibration analysis of uniform and stepped circular cylindrical shells using a domain decomposition method," Applied Acoustics, vol. 74, no. 3, pp. 425-439, 2013.

[28] Y. Qu, Y. Chen, Y. Chen, X. Long, H. Hua, and G. Meng, “A domain decomposition method for vibration analysis of conical shells with uniform and stepped thickness," Journal of Vibration and Acoustics, vol. 135, no. 1, article 011014, 2013.

[29] L. Zhang and Y. Xiang, "Exact solutions for vibration of stepped circular cylindrical shells," Journal of Sound and Vibration, vol. 299, no. 4-5, pp. 948-964, 2007.

[30] A. M. Khalifa, "Exact solutions for the vibration of circumferentially stepped orthotropic circular cylindrical shells," Comptes Rendus Mécanique, vol. 339, no. 11, pp. 708-718, 2011.

[31] F. A. Fazzolari, "A refined dynamic stiffness element for free vibration analysis of cross-ply laminated composite cylindrical and spherical shallow shells," Composites Part B: Engineering, vol. 62, pp. 143-158, 2014.

[32] K. Xie, M. Chen, and Z. Li, "An analytic method for free and forced vibration analysis of stepped conical shells with arbitrary boundary conditions," Thin-Walled Structures, vol. 111, pp. 126-137, 2017.

[33] A. W. Leissa, Vibration of the Shells NASA SP-288, US Government Printing Office, Washington, DC, USA, 1973.

[34] E. Ventsel and T. Krauthammer, Thin Plates and Shells: Theory-Analysis, and Applications, CRC Press, Boca Raton, FL, USA, 2001.

[35] O. C. Zienkiewicz, R. L. Taylor, and J. M. Too, "Reduced integration technique in general analysis of plates and shells," International Journal for Numerical Methods in Engineering, vol. 3, no. 2, pp. 275-290, 1971.

[36] A. H. Bhrawy, T. M. Taha, and J. A. T. Machado, "A review of operational matrices and spectral techniques for fractional calculus," Nonlinear Dynamics, vol. 81, no. 3, pp. 1023-1052, 2015. 
[37] L. E. Monterrubio, "Free vibration of shallow shells using the Rayleigh-Ritz method and penalty parameters," Proceedings of the Institution of Mechanical Engineers, Part C: Journal of Mechanical Engineering Science, vol. 223, no. 10, pp. 22632272, 2009.

[38] D. Sármány, F. Izsák, and J. J. W. van der Vegt, "Optimal penalty parameters for symmetric discontinuous Galerkin discretisations of the time-harmonic Maxwell equations," Journal of Scientific Computing, vol. 44, no. 3, pp. 219-254, 2010.

[39] E. Artioli and E. Viola, "Free vibration analysis of spherical caps using a G.D.Q. numerical solution," Journal of Pressure Vessel Technology, vol. 128, no. 3, pp. 370-378, 2006. 


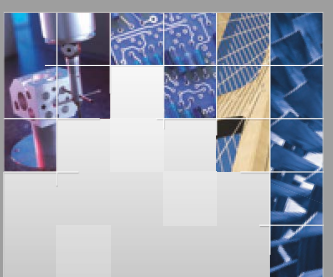

\section{Enfincering}
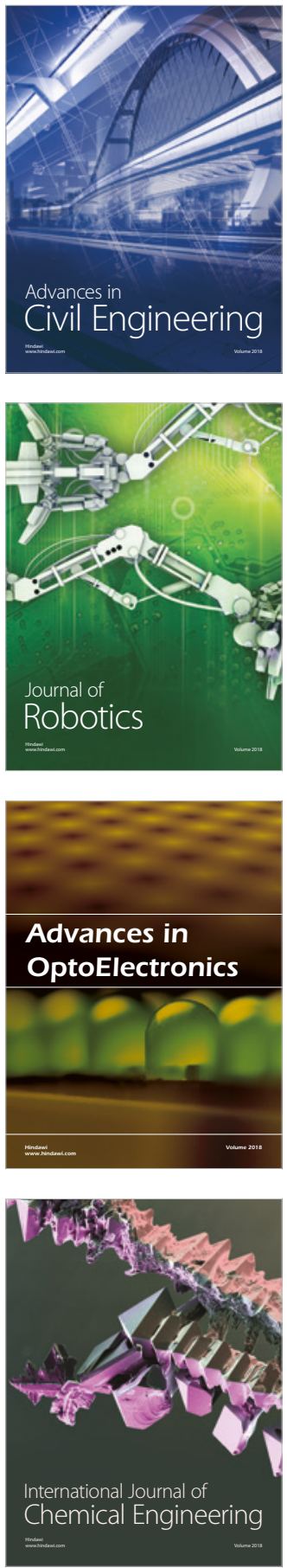

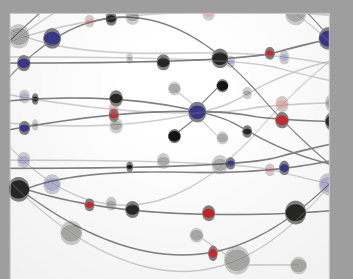

\section{Rotating \\ Machinery}

The Scientific World Journal

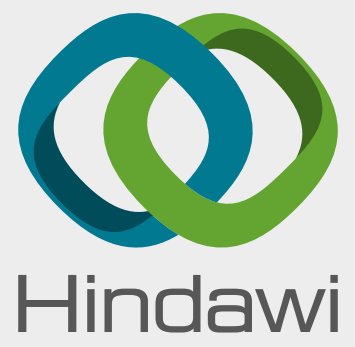

Submit your manuscripts at

www.hindawi.com
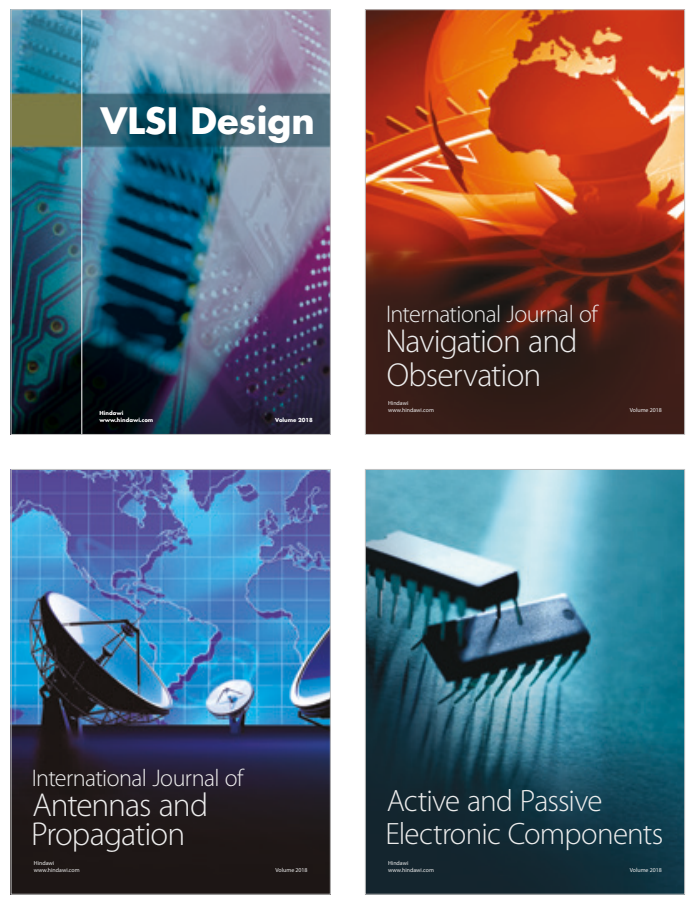
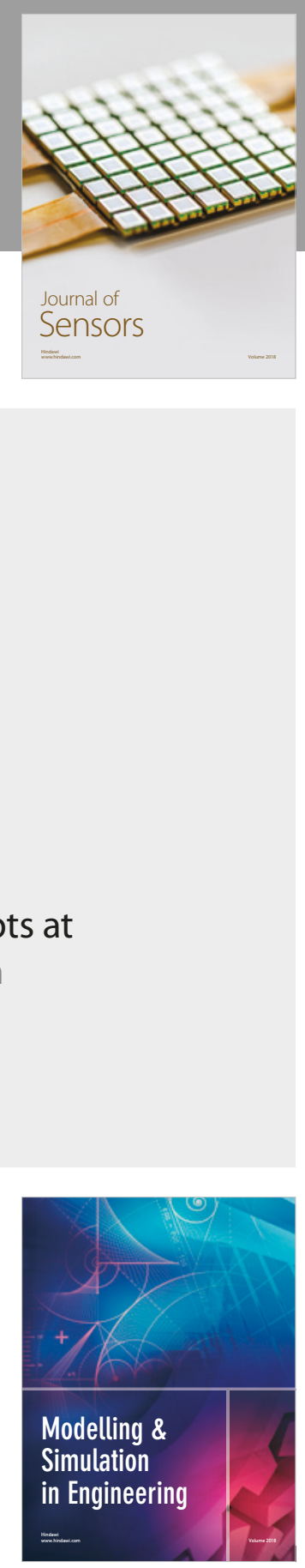

\section{Advances \\ Multimedia}
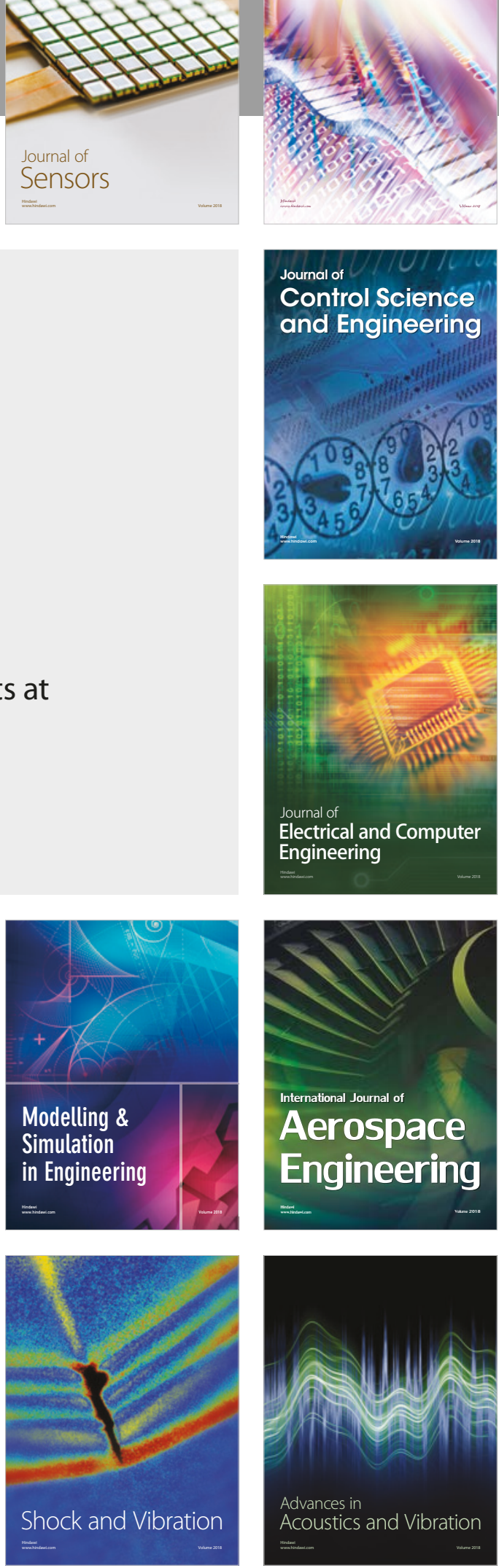